NBER WORKING PAPER SERIES

\title{
THE BURDEN OF KNOWLEDGE AND THE 'DEATH OF THE RENAISSANCE MAN': IS INNOVATION GETTING HARDER?
}

\author{
Benjamin F. Jones \\ Working Paper 11360 \\ http://www.nber.org/papers/w11360
NATIONAL BUREAU OF ECONOMIC RESEARCH 1050 Massachusetts Avenue
Cambridge, MA 02138
May 2005

I wish to thank Pol Antras, Andrei Bremzen, Esther Duflo, Glenn Ellison, Amy Finkelstein, Simon Johnson, Joel Mokyr, Ben Olken, Michael Piore, Scott Stern and participants at various lunches and seminars for helpful comments. I am especially grateful to Daron Acemoglu, Abhijit Banerjee, and Sendhil Mullainathan for their advice and Trevor Hallstein for research assistance. The support of the Social Science Research Council's Program in Applied Economics, with funding provided by the John D. and Catherine T. MacArthur Foundation, is gratefully acknowledged. The views expressed herein are those of the author(s) and do not necessarily reflect the views of the National Bureau of Economic Research.

(C)2005 by Benjamin F. Jones. All rights reserved. Short sections of text, not to exceed two paragraphs, may be quoted without explicit permission provided that full credit, including $\odot$ notice, is given to the source. 
The Burden of Knowledge and the 'Death of the Renaissance Man': Is Innovation Getting Harder? Benjamin F. Jones

NBER Working Paper No. 11360

May 2005

JEL No. O3, O4, J2, I2

\begin{abstract}
$\underline{\text { ABSTRACT }}$
This paper investigates, theoretically and empirically, a possibly fundamental aspect of technological progress. If knowledge accumulates as technology progresses, then successive generations of innovators may face an increasing educational burden. Innovators can compensate in their education by seeking narrower expertise, but narrowing expertise will reduce their individual capacities, with implications for the organization of innovative activity - a greater reliance on teamwork - and negative implications for growth. I develop a formal model of this "knowledge burden mechanism" and derive six testable predictions for innovators. Over time, educational attainment will rise while increased specialization and teamwork follow from a sufficiently rapid increase in the burden of knowledge. In cross-section, the model predicts that specialization and teamwork will be greater in deeper areas of knowledge while, surprisingly, educational attainment will not vary across fields. I test these six predictions using a micro-data set of individual inventors and find evidence consistent with each prediction. The model thus provides a parsimonious explanation for a range of empirical patterns of inventive activity. Upward trends in academic collaboration and lengthening doctorates, which have been noted in other research, can also be explained by the model, as can much-debated trends relating productivity growth and patent output to aggregate inventive effort. The knowledge burden mechanism suggests that the nature of innovation is changing, with negative implications for long-run economic growth.

Benjamin F. Jones

Northwestern University

Kellogg School of Management

Department of Management and Strategy

2001 Sheridan Road

Evanston, IL 60208

and NBER

bjones@kellogg.northwesterm.edu
\end{abstract}




\section{$1 \quad$ Introduction}

Understanding innovation is central to understanding many important aspects of economics, from market structure to aggregate growth. Innovators, in turn, are a necessary input to any innovation. The innovator, wrestling with a creative idea, working with colleagues, bringing an idea to fruition, seems the very heart of the innovative process.

This paper places innovators at the center of analysis and focuses on two simple observations. First, innovators are not born at the frontier of knowledge; rather, they must initially undertake significant education. Second, the frontier of knowledge shifts over time. The purpose of this paper is to investigate equilibrium implications of these two observations and then test these implications empirically. The theory and empirical work below suggest possibly fundamental consequences for the organization of innovative activity and, in the aggregate, for growth.

The first observation concerns human capital and highlights a general distinction between human capital and other stock variables. Physical stocks can be transferred easily, as property rights, from one agent to another. Human capital, by contrast, is not transferred easily. While one generation may rather effortlessly bequeath its physical assets to the next, with human capital stocks, this is fundamentally not the case. The vessel of human capital - the individual - absorbs information at a limited rate, has limited capacity, and has limited time on earth. The difficulty of transferring human capital has broad implications in economics ${ }^{1}$; in this paper, I focus on basic implications for innovation.

The second observation concerns the total stock of knowledge. In 1676, Isaac Newton wrote famously to Robert Hooke, "If I have seen further it is by standing on the shoulders of giants." Newton's sentiment suggests that knowledge begets new knowledge, an observation that has been formalized in the growth literature (Romer 1990, Jones 1995a, Weitzman 1998) with implications discussed extensively both there (e.g. Jones 1995b, Kortum 1997, Young 1998) and in the micro-innovation literature (e.g. Scotchmer 1991, Henderson \& Cockburn 1996). This paper suggests a different, indirect implication of Newton's observation: if one is to stand on the shoulders of giants, one must first climb up their backs, and the greater the body of knowledge, the harder this climb becomes.

\footnotetext{
${ }^{1}$ See, for example, Ben-Porath (1967) regarding life-cyle earnings and Hart \& Moore (1995) regarding debt contracts.
} 
If technological progress leads to an accumulation of knowledge, then the educational burden on successive cohorts of innovators will increase. Innovators might confront this difficulty by choosing to learn more. Alternatively, they might compensate by choosing narrower expertise - a "death of the Renaissance Man" effect. Choosing to learn more will leave less time in the life-cycle for innovation. Narrowing expertise, meanwhile, can reduce individual capabilities and force innovators to work in teams. Intriguing evidence along the lines of a "learning more" effect can be seen in Table 1, which borrows from Jones (2005). We see that the mean age at which great inventors and Nobel Prize winners produced their great innovations increased by 6 years over the course of the 20th Century. To help motivate the second set of effects, consider the invention of the microprocessor. As described by Malone (1995), the invention was by necessity the work of a team. The inspiration began with a researcher named Ted Hoff, who joined in the theoretical development with Stan Mazor. But as Malone writes,

Hoff and Mazor didn't really know how to translate this architecture into a working chip design... The project began to lag.

In fact, probably only one person in the world did know how to do the next step. That was Federico Faggin...

The microprocessor was one person's inspiration, but several people's invention. It is the story of researchers with circumscribed abilities, working in a team, and it helps motivate the model of innovation and the empirical work in this paper.

In the model, presented in Section 2, innovators are specialists who interact with each other in the implementation of their ideas. The model introduces a "circle of knowledge" - a continuum of types of knowledge - upon which innovators define their specialties and locate necessary teammates. Achieving expertise in any area on the circle requires an innovator to bring herself to the frontier of knowledge in that area, and the difficulty of reaching the frontier - the burden of knowledge - may increase or decrease over time.

The central choice problem is that of career. At birth, each individual chooses to become either a production worker or an innovator. Innovators must further choose a specific area of knowledge to learn. They choose their degree of specialization as a tradeoff between the costs and benefits of education: greater knowledge leads to increased innovative potential, but it also costs more to acquire. Innovators also seek to avoid crowding: other things equal, 
the greater the density of innovators in a particular area of knowledge, the less expected income each will earn. The equilibrium defines the educational decisions of innovators - the total amount of education they seek, their degree of specialization, and their consequent propensity to form teams.

Career choices are made in a dynamically evolving economy. The model marries the burden of knowledge mechanism with two established insights in the growth and innovation literatures. First, a growing population increases market size, making innovations more valuable and attracting workers to the innovative sector. The importance of introducing such scale effects from an aggregate growth perspective was first pointed out by Jones (1995a). In this model, increasing market size also plays a key role by increasing the marginal value of education, thereby increasing the amount of education innovators wish to seek. Second, the value of knowledge may be increasing or decreasing as the economy evolves. This feature captures, in reduced-form, a broad range of arguments in the literature: both fishing-out ideas (e.g. Kortum 1997), as well as more optimistic specifications where knowledge is increasingly useful (e.g. Romer 1990, Aghion \& Howitt 1992). An increasing value of knowledge will tend, ceteris paribus, to increase the marginal benefit of education. Finally, the difficulty in reaching the knowledge frontier - the burden of knowledge - may rise or fall as the economy evolves.

In this framework the same forces that influence innovators' educational decisions also influence long-run growth. Indeed, the tight link between individual income possibilities and changes in the knowledge space produces detailed predictions about innovator behavior on the one hand and aggregate consequences on the other, allowing this model to explain both micro and aggregate data patterns. The crux of the model is that income possibilities determine career decisions. Therefore, any increase in the burden of knowledge cannot be analyzed in isolation but must be weighed against both the value of this knowledge and other income opportunities when innovators make their career choices. Moreover, any simple intuition that areas of "greater knowledge" require more education and/or more specialization turns out to have important and empirically relevant qualifications. Along the balanced growth path, the income possibilities of innovation expand - because market size and/or the value of ideas are increasing - so that new cohorts will seek more education over time. Given this increasing educational attainment, innovators will only become more specialized if the burden of knowledge mechanism is sufficiently strong. More subtly, 
income arbitrage produces the surprising result that educational attainment will not vary across technological fields, regardless of variation in the burden of knowledge or innovative opportunities.

In all, the model makes six testable predictions for the behavior of individual innovators. In time series, the model predicts that (i) educational attainment will be rising while (ii) specialization and (iii) teamwork will increase only if the burden of knowledge is increasing at a sufficient rate. In cross-section, the model predicts that (iv) specialization and hence (v) teamwork will be greater in fields where knowledge is deeper. At the same time, (vi) educational attainment should show no variation across technological fields.

Section 3 tests these six predictions empirically. Using a rich patent data set (Hall et al. 2001) together with the results of a new data collection exercise to determine the ages of 55,000 inventors, I am able to develop detailed patent histories for individuals. As shown in Figure 1, I find that the age at first innovation, which can serve as a proxy measure for educational attainment, is trending upwards at 0.6 years per decade. Meanwhile, U.S. team size is seen to be increasing at a remarkably steep rate of $17 \%$ per decade, and a direct measure for specialization is increasing by $6 \%$ per decade. As discussed in Section 3, these trends are all robust to a number of controls, and in particular are robust across a wide range of technological categories and research environments.

In cross-section, I find striking support for the model's perhaps less obvious prediction that educational attainment will be similar across fields. At the same time, team size and the specialization measure vary substantially across fields, and, as predicted, are larger where the amount of knowledge underlying each patent is larger.

The model thus serves as a parsimonious explanation for this collection of new facts. Starting with simple observations about human capital and knowledge, we are led to test basic predictions about innovator behavior and to uncover substantial variations across fields and over time. As discussed in Section 4, the model can further explain several facts that have been documented elsewhere, including upward trends in academic coauthorship and doctoral duration. Lastly, in the aggregate, the model provides one consistent explanation for existing facts debated by growth economists. First, R\&D employment in leading economies has been rising dramatically, yet TFP growth has been flat (Jones, 1995b). Second, the average number of patents produced per $R \& D$ worker or $R \& D$ dollar has been falling over time across countries (Evenson 1984) and U.S. manufacturing industries (Kor- 
tum 1993). These aggregate data trends can be seen in the model as an effect of increasingly narrow expertise, where innovators are becoming less productive as individuals and are required to work in ever larger teams.

Section 4 reviews the results, connects them to existing literatures, and further discusses their implications.

\section{The Model}

The over-arching theme of this model is the emphasis on innovators. I analyze a simple structure with two sectors: a production sector where competitive firms produce a homogenous output good and an innovation sector where innovators produce productivity-enhancing ideas. Workers in the production sector earn a competitive wage while innovators earn income by licensing their ideas to firms in the production sector. I abstract from physical capital and focus on the role of human capital in the innovation sector. Innovators must undertake a costly human capital investment to bring themselves to the knowledge frontier where they become able to innovate. Innovators face a tradeoff between the costs of seeking more education and the benefits of achieving a broader degree of expertise. This tradeoff will be balanced differently by different cohorts as the economy evolves.

Section 2.1 describes the production sector and Section 2.2 defines individuals' lifecycles and preferences. Sections 2.3 and 2.4 focus on innovators. The first describes the knowledge space and the cost of education. The second considers the innovation process and the value of ideas. Section 2.5 defines individuals' equilibrium choices. Section 2.6 analyzes steady-state growth, and Section 2.7 examines the time-series predictions of the model. Section 2.8 extends the model to investigate its predictions across technological areas at a point in time. The predictions of Sections 2.7 and 2.8 are the foundation for the empirical analysis in Section 3.

\subsection{The Production Sector}

Competitive firms in the production sector produce a homogenous output good. A firm $j$ hires an amount of labor, $l_{j}(t)$, to produce output, $y_{j}(t)=X_{j}(t) l_{j}(t)$. The productivity level of firm $j$ is $X_{j}(t) \leq X(t)$, where $X(t)$ is the leading edge of productivity in the economy, which can be achieved by any firm with access to the entire set of productive ideas. 
The firm pays workers a wage, $w(t)$, and makes royalty payments per worker of $r(t)$ on any patented technologies it employs. While patent protection lasts, the monopolist innovator will charge a firm a fee, per period, equivalent to all the extra output the firm can produce with the innovation, and the firm will be just willing to pay this fee. Therefore $X_{j}(t)=X(t) \forall j$, and the total output in the economy is:

$$
Y(t)=X(t) L_{Y}(t)
$$

The revenues of these competitive firms are dispensed entirely in wage and royalty payments, $X(t) l_{j}(t)=w(t) l_{j}(t)+r(t) l_{j}(t)$. The competitive wage paid to a production worker is therefore:

$$
w(t)=X(t)-r(t)
$$

\subsection{Workers and Preferences}

There is a continuum of workers of measure $L(t)$ in the economy at time $t$. This population grows at rate $g_{L}$. Individuals are risk neutral and face a constant hazard rate $\phi$ of death. They share a common intertemporal utility function, ${ }^{2}$

$$
U(\tau)=\int_{\tau}^{\infty} c(t) e^{-\phi(t-\tau)} d t
$$

I assume that individuals are born without assets and supply a unit of labor inelastically at all points over their lifetime. From the standard intertemporal budget constraint, the individual's utility is equivalent to the present value of her expected lifetime non-interest income.

The choice problem is that of career. At birth, an individual decides whether to become a wage worker or an innovator. Wage workers require no education and their expected utility is simply the discounted flow of the wage payments they receive:

$$
U^{\text {wage }}(\tau)=\int_{\tau}^{\infty} w(t) e^{-\phi(t-\tau)} d t
$$

If an individual $i$ chooses to be an innovator instead, then she must further choose a specific field of expertise and pay an immediate fixed cost of education, $E$, to bring herself

\footnotetext{
${ }^{2}$ For simplicity of exposition, I will specify the incomes and expenditures in the model in terms of a unit-mass of individuals.
} 
to the frontier of knowledge in that area. Having paid this cost, the innovator earns an expected flow of income, $v$, by licensing any innovations she produces to firms in the production sector. In the model, both $v$ and $E$ are specific to the choice of expertise made by an individual $(i)$. The educational cost will also depend on the state of knowledge at the time of birth $(\tau)$, and income flows will further depend on the current state of the economy $(t)$. The expected lifetime utility of an innovator is written generally as,

$$
U_{i}^{R \& D}(\tau)=\int_{\tau}^{\infty} v_{i}(t) e^{-\phi(t-\tau)} d t-E_{i}(\tau)
$$

The structure of the innovator's educational choice and the functional forms of $v$ and $E$ are the subject of the next two subsections.

Note that an extended model can further allow for educational time, so that education has an opportunity cost (foregone income) in addition to any out-of-pocket cost. The simpler model presented here provides the same themes as the extended model, so this paper will feature the simpler case; the extended model is provided in the Appendix.

\subsection{Knowledge and Education}

A type of knowledge is defined by its position, $s$, on the unit circle. For example, one segment of the circle might represent electronics, another biochemistry, another economics. At a point in time, the amount of knowledge at each point on the circle is assumed to be the same. ${ }^{3}$ I define this quantity as $D(t)$.

The prospective innovator chooses an area of expertise: a point, $s_{i}$, on the circle and a certain distance, $b_{i} \in[0,1]$, to its right. For an innovator born at time $\tau$, the amount of knowledge the innovator acquires is the chosen breadth of expertise, $b_{i}$, multiplied by the prevailing depth of knowledge, $D(\tau)$. The educational cost of acquiring this information is:

$$
E_{i}(\tau)=\left(b_{i} D(\tau)\right)^{\varepsilon}
$$

where $\varepsilon>0$, which says only that learning more requires a greater amount of education. I make no a priori assumption about whether education costs are convex or concave in the amount of information the innovator learns.

\footnotetext{
${ }^{3}$ I will partly relax this assumption when I consider a cross-sectional variation of the model in Section 2.8 .
} 
With the assumption that the depth of knowledge is evenly arrayed around a unit circle, the total depth of knowledge at a point in time is $D(t)$. In general, the depth of knowledge will change as innovators produce new ideas. However, while these new ideas serve to increase the productivity in the economy, $X(t)$, they may or may not increase $D(t)$. I write,

$$
D(t)=(X(t))^{\delta}
$$

with no assumption regarding the sign of $\delta$. It may be natural to assume that the production of new ideas in the $\mathrm{R} \& \mathrm{D}$ sector leads to an increase in $D(t)$ - a rising burden of knowledge. However, we might also imagine that new ideas either replace old ideas or simplify ideas so that $D(t)$ may actually fall as productivity rises. This latter interpretation is consistent with the concept of revolutionary "paradigm shifts", which Thomas Kuhn has suggested as the appropriate model of scientific progress (Kuhn 1962).

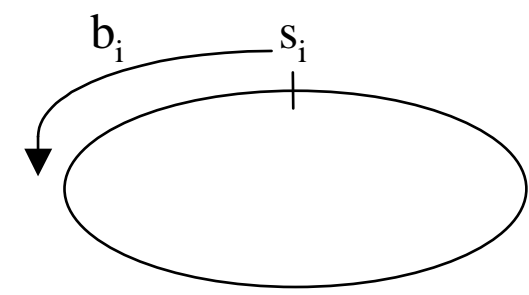

Figure 2: The circle of knowledge

\subsection{Innovation}

Once educated, innovators begin to receive innovative ideas. Ideas arrive randomly, with hazard rate $\lambda$ for a unit-mass of individuals. When an idea arrives, it comes with two further properties. The first is the random breadth of expertise, $k$, required to implement the idea. The second is the size of the idea, which adds to TFP by an amount $\gamma{ }^{4}$

The required expertise, $k$, may be greater or less than the inspired innovator's own expertise, $b_{i}$. The breadth of the idea $k \in[0,1]$ is drawn from a smooth distribution function $F$. It is measured as a distance to the right from an individual's location $s_{i}$, so that the implementation of the idea requires expertise over the segment of the circle $\left[s_{i}, s_{i}+k\right]$. Therefore, with probability $F\left(b_{i}\right)$ the innovator is able to implement the idea

\footnotetext{
${ }^{4}$ One can imagine more generally that the size of ideas is random, where $\gamma$ is the mean size; this interpretation has no effect on the model.
} 
alone, and with probability $1-F\left(b_{i}\right)$ the innovator needs at least one partner. That is, I allow for the formation of teams.

I assume that the innovator with the idea acts as a monopolist vis-a-vis potential teammates so that, by Bertrand reasoning, the inspired innovator receives all profits from the project. I further assume that once an idea arrives it can be implemented instantaneously and without any expenditure (in particular, team formation is costless). Therefore, (i) all projects are profitable, (ii) the inspired, monopolist innovator will receive the entire royalty stream from the project as personal income, and (iii) any necessary teammates will be just willing to help without compensation. ${ }^{5}$

I make two further assumptions regarding team formation. The inspired innovator will choose team members from her own cohort if possible and assemble the minimum number of people necessary to implement the idea. These assumptions are innocuous and are made to permit explicit analysis of average team size in Sections 2.7 and 2.8.

Given that an idea can be licensed for use by $L_{Y}$ workers, and patent protection lasts for $z$ years, the market size for a patent is:

$$
M(t)=\int_{t}^{t+z} L_{Y}(\widetilde{t}) d \widetilde{t}
$$

and the lump-sum value of the patent is therefore $V(t)=\gamma M(t) .{ }^{6}$

The expected flow of income to an innovator is $v=\lambda V$, the probability of having an idea at a point in time times the income the idea generates. Using the definition of $V$, we can write $v=\lambda \gamma M$. The expected flow of income is therefore equivalently understood as the expected rate at which the innovator adds to TFP, $\lambda \gamma$, times the market size for the innovation. When considering the time lag between an innovator's innovations, it will be useful to consider $\lambda$ and $\gamma$ separately. However, in determining equilibrium choices, I wish to emphasize that the combination of these parameters is the important primitive. I will

\footnotetext{
${ }^{5}$ The only possible obstacle to implementation is an absence of required expertise. Anticipating the equilibrium of this model, innovators' collective expertise will cover the entire circle of knowledge, so that all ideas are feasible and therefore all ideas will in fact be implemented. To avoid burdensome notation in the text, I will write the rest of the model assuming this result. The Appendix considers the general case and establishes this result as part of any (subgame perfect) equilibrium.

${ }^{6}$ This expression is written assuming the innovator has access to a competitive financial market which will pay the innovator the lump-sum value of the patent (or an equivalent annuity) in exchange for the patent rights. If no such market were available, the value of the patent to the innovator would need to reflect the possibility that the innovator dies before the patent rights expire, in which case $V=\gamma \int_{t}^{t+z} L_{Y}(\widetilde{t}) e^{-\phi(\widetilde{t}-t)} d \widetilde{t}$. This variation will have no impact on the main results of the model.
} 
therefore define $\theta=\lambda \gamma$ as a summary measure of innovator productivity and, for brevity, proceed in defining the final pieces of the model on the basis of $\theta$.

Specifically, I assume that innovator productivity will depend on three things: (1) the level of technology; (2) the current degree of competition in the innovator's specialty; and (3) the innovator's breadth of expertise. In particular, I write,

$$
\theta_{i}(t)=X(t)^{\chi} L\left(t, s_{i}\right)^{-\sigma} b_{i}^{\beta}
$$

where $X(t)$ is the productivity level in the economy, $L\left(t, s_{i}\right)$ is the mass of individuals at time $t$ who share the innovator's specialty, and $b_{i}$ is the innovator's breadth of expertise.

These reduced-form specifications capture several key ideas. The parameter $\chi$ represents the impact of the state of technology on an innovator's productivity. It incorporates the standard ideas in the literature which were alluded to in the introduction: "fishingout" hypotheses whereby innovators' productivity falls as the state of knowledge advances $(\chi<0)$, and "positive intertemporal spillovers" whereby an improving state of knowledge makes innovators more productive $(\chi>0){ }^{7}$

The parameter $\sigma$ represents the impact of crowding on the frequency of an innovator's ideas. I assume $\sigma>0$, following standard arguments where innovators partly duplicate each other's work. A greater density of workers in the same specialty increases duplication, reducing the rate at which a specific individual produces a novel idea.

The final parameter, $\beta$, represents the impact of the breadth of expertise. A specification with $\beta>0$ suggests simply that greater human capital increases one's productivity. The specific reason I embrace, for the purposes of this model, is that individuals with broader expertise access a larger set of available knowledge - facts, theories, methods - on which to build innovations. This will increase their innovative abilities, along the lines of Weitzman (1998), making them more productive. ${ }^{8}$

\footnotetext{
${ }^{7}$ Note that I am using the state variable $X(t)$ to represent the effect of both technology and the state of knowledge on an innovator's capabilities. Adding a separate channel to differentiate between "ideas" and "technology" will add little insight. When I discuss cross-sectional predictions in Section 2.8, where it will be useful to think of different knowledge levels across technological areas, I will introduce a richer specification.

${ }^{8}$ There are many other mechanisms through which broader expertise would enhance an innovator's income. First, a more broadly expert innovator may better evaluate the expected impact and feasibility of her ideas. She will better select toward high value, successful lines of inquiry, and therefore achieve greater returns. Second, if assembling teams is costly, innovators will be unwilling to form large teams. More broadly expert innovators can rely less on large teams for the implementation of their ideas, making their ideas less costly to implement. Third, if income is shared across team members, then broader expertise,
} 
Finally, I can now explicitly define an innovator's expected flow of income,

$$
v_{i}(t)=X(t)^{\chi} L\left(t, s_{i}\right)^{-\sigma} b_{i}^{\beta} M(t)
$$

\subsection{Equilibrium Choices}

The choice facing each individual is that of career, which is a one-shot decision made at birth. Define the set of individuals born at time $\tau$ as $l(\tau)$, of which a subset $l_{Y}(\tau)$ choose the production sector and a subset $l_{R}(\tau)$ choose the innovation sector instead. Those who choose the innovation sector must additionally choose an area of expertise $(s, b)$. In equilibrium, we require two conditions for each cohort $\tau$ :

$$
\begin{aligned}
U_{i}^{R \& D}\left(s_{i}, b_{i}\right) & \geq U_{i}^{R \& D}(s, b) \quad \forall s, b \quad \forall i \in l_{R}(\tau) \\
U_{i}^{R \& D}(\tau) & =U^{\text {wage }}(\tau)=U^{*}(\tau) \quad \forall i \in l_{R}(\tau) \quad \forall j \in l_{Y}(\tau)
\end{aligned}
$$

The first condition states that no innovator can deviate to any other educational choice and be better off. The second condition rules out income arbitrage possibilities between the $\mathrm{R} \& \mathrm{D}$ and production sectors. With the definitions of the model in Sections 2.1 through 2.4 , we can now define the expected income from various choices and hence, with conditions (11) and (12), the equilibrium outcome.

\subsubsection{Production workers}

Production workers receive a competitive wage $w(t)=X(t)-r(t)$, as defined in (2). Since patents are protected for $z$ years, the flow of royalty payments $r(t)$ is simply $X(t)-X(t-z)$ and therefore $w(t)=X(t-z)$. In other words, the wage earned by a production worker is that portion of productivity which is not patent-protected, which is just the productivity level of the economy $z$ years previously.

Choosing to be a production worker therefore provides lifetime income of

$$
U^{*}(\tau)=\int_{\tau}^{\infty} X(t-z) e^{-\phi(t-\tau)} d t
$$

which reduces the necessary team size, will bring one a greater share of project income. These last two effects will lead more narrowly expert innovators to abandon a greater portion of their broad ideas. 


\subsubsection{Innovators}

The innovator makes an educational choice to maximize lifetime income. With the objective function (5), and given the definitions for education cost and expected income flow in (6) and (10), the innovator's problem is:

$$
\max _{s_{i}, b_{i}} \int_{\tau}^{\infty} X(t)^{\chi} L\left(t, s_{i}\right)^{-\sigma} b_{i}^{\beta} M(t) e^{-\phi(t-\tau)} d t-\left(b_{i} D(\tau)\right)^{\varepsilon}
$$

Proposition 1 Innovators choose a pair $\left(s_{i}^{*}, b_{i}^{*}\right)$ such that

(i) $L\left(t, s_{i}^{*}\right)=L_{R}(t)$

(ii) $E^{*} / U^{*}=$ constant

(iii) $b_{i}^{*}=b^{*}(\tau)$

The proofs for all propositions and their corollaries are presented in the Appendix.

Result (i) says that innovators will evenly array themselves around the circle of knowledge. The intuition is straightforward. Given that $\sigma>0$, duplication lowers income. In consequence, the innovator seeks to avoid crowding and chooses a location where the density of innovators is smallest. In equilibrium, no innovator will wish to deviate from her choice of $s_{i}$, in which case all innovators must array themselves evenly around the unit circle.

Result (ii) says that educational expenditure and lifetime income are in constant ratio across individuals and cohorts. This result follows from the choice of the breadth of expertise, $b_{i}$. The innovator chooses $b_{i}$ so that the marginal cost of education equals the marginal expected benefit to her income. The isoelastic properties of $v$ and $E$ with respect to the breadth of expertise then guarantee a constant ratio of $E^{*} / U^{*}$. This type of result is familiar from Cobb-Douglass type specifications. The innovator pays an additive cost to acquire $b$, the breadth of expertise, which is an isoelastic input to the innovator's "production function", $v$. As is well known from the Cobb-Douglass case, the expenditure share on the input is a constant fraction of the income. This result is a key property of the equilibrium, from which many other results will follow. As a first example, the third part of the proposition follows directly. Arbitrage in career choices implies that $U^{*}$ must be the same across individuals in the same cohort. Therefore, since $E^{*} / U^{*}$ is constant, educational expenditure $\left(E^{*}\right)$ must also be constant across innovators within a cohort, implying a common breadth of expertise $\left(b^{*}\right)$. 


\subsection{Steady-state Growth}

Given Proposition 1, we will now examine the balanced-growth path and consider the implications of the knowledge burden mechanism for aggregate growth. If there are $L_{R}(t)$ innovators active at a point in time and innovators raise productivity in the economy on average at a rate $\bar{\theta}(t)$, then productivity increases per unit of time are simply $d X / d t=$ $\bar{\theta}(t) L_{R}(t)$. The growth rate of productivity is then,

$$
g=\frac{\bar{\theta}(t) L_{R}(t)}{X(t)}
$$

This expression is mechanical and holds both inside and outside of steady-state. On the balanced growth path we can further re-express $g$ as function of exogenous parameters.

Proposition 2 Along a balanced growth path, the growth rate is

$$
g=\frac{1-\sigma}{1-\chi+\beta\left(\delta-\frac{1}{\varepsilon}\right)} g_{L}
$$

where $\chi-\beta\left(\delta-\frac{1}{\varepsilon}\right)<1$.

This result, with its parametric condition, defines the growth rate as the outcome of several important forces. First, the parameter $\chi$, as discussed above, represents standard ideas in the growth literature whereby the productivity of innovators may increase as they gain access to new technologies and new ideas $(\chi>0)$ or decrease if innovators are fishing out ideas $(\chi<0)$. The larger $\chi$ - the greater the value of new knowledge - the greater the growth rate, as is seen in (16).

Second, the term $\beta\left(\delta-\frac{1}{\varepsilon}\right)$ captures the implications of the burden of knowledge. The term $\left(\delta-\frac{1}{\varepsilon}\right)$ defines how the breadth of expertise changes along the growth path. As shown in the Appendix in the proof of (16),

$$
g_{b^{*}}=-\left(\delta-\frac{1}{\varepsilon}\right) g
$$

so that new cohorts of innovators become more specialized with time if and only if $\delta>1 / \varepsilon$. This specialization condition is intuitive: it says that people will specialize more with time if the depth of knowledge in the economy rises relatively quickly given the ease with which knowledge can be learned. ${ }^{9}$ If this condition is satisfied, we will witness the "death of

\footnotetext{
${ }^{9}$ Recall that $\delta$ is the elasticity of knowledge depth to the level of productivity, and $\varepsilon$ is the elasticity of educational cost to the amount of knowledge learned.
} 
the Renaissance Man" along the growth path $\left(g_{b^{*}}<0\right)$. The impact of specialization on growth will be large or small depending on the value of $\beta$, which defines the sensitivity of innovators' productivity to their breadth of expertise. ${ }^{10}$

Expression (16) also shows that growth in per-capita income depends on population growth, $g_{L}$. This is the standard Jones (1995b) style result, where increasing effort is needed to produce steady-state growth. A growing population provides both the motive increasing market size - and the means - more minds - for innovative effort to grow at an exponential rate, even if innovation is getting harder. The alternative, Romer (1990) style result, where growth can be sustained with constant effort, is obtained in the knife-edge case where $\chi-\beta\left(\delta-\frac{1}{\varepsilon}\right)=1 .^{11}$ The burden of knowledge mechanism (captured by $\beta\left(\delta-\frac{1}{\varepsilon}\right)$ ) is therefore felt either by (i) pushing us toward a world where ever-increasing effort is needed to sustain steady growth or (ii) producing lower growth rates given that we are already in that world.

Essentially, the greater the growth in the burden of knowledge, the greater must be the growth in the value of knowledge to compensate. Articulated views of why innovation may be getting harder in the growth literature (Kortum 1997, Segerstrom 1998) have focused on a "fishing out" idea; that is, on the parameter $\chi$. The innovation literature also tends to focus on "fishing out" themes (e.g. Evenson 1991, Cockburn \& Henderson, 1996). This paper offers the burden of knowledge as an alternative mechanism, one that makes innovation harder, acts similarly on the growth rate, and can explain aggregate data trends (see Section 4). Most importantly, the model makes specific predictions about the behavior of individual innovators, allowing one to get underneath the aggregate facts and test for a possible rising burden of knowledge using micro-data. These predictions are defined in the next two sub-sections.

\subsection{Time Series Predictions}

Given the equilibrium properties defined in Proposition 1, we can derive three features of innovator behavior over time.

\footnotetext{
${ }^{10}$ In a model with a time cost for education, an increasing burden of knowledge is also felt through increased educational time, as this reduces the portion of the life-cycle left over to actively pursue innovations. The Appendix considers this more general model.

${ }^{11}$ Of course, if $\chi+\beta\left(\frac{1}{\varepsilon}-\delta\right)=1$ then growth will explode if $g_{L}>0$ (see (16)). This "scale effect" makes this knife-edge case inconsistent with aggregate data patterns, a problem discussed in detail elsewhere (Jones 1995b; Jones 1999).
} 
Corollary 1 Along the balanced growth path

(i) $g_{E^{*}}=g$

(ii) $g_{b^{*}}<0$ iff $\delta>1 / \varepsilon$

(iii) $\overline{\text { team }}(t)>0$ iff $\delta>1 / \varepsilon$

The first result says that educational attainment of successive cohorts increases along the growth path. Since the value of education to innovators is complementary to growing income possibilities - due to increasing market size if nothing else - innovator cohorts will seek more education over time. In equilibrium the optimal amount of education is a fixed fraction of the innovator's lifetime income - see Proposition 1. As the economy grows, individual incomes grow at rate $g$. In consequence, the amount of education innovators seek also grows at rate $g .{ }^{12}$

Note that increasing educational attainment is not driven in equilibrium by an increasing educational burden: rather, it is driven by the expanding benefits that education affords. Along the growth path, educational attainment will rise regardless of whether the distance to the frontier is increasing.

This equilibrium property provides further intuition for the second result, regarding specialization, which was discussed in the prior section. Increasing educational attainment implies that $\delta>1 / \varepsilon$, rather than $\delta>0$, is required for expertise to narrow along the growth path. That is, given increasing educational attainment, the knowledge stock must not only grow, but grow at a sufficiently high rate to result in narrowing expertise. The third result, the behavior of average team size, $\overline{\text { team }}(t)$, follows the same condition as specialization. This result should seem intuitive: more specialized workers rely more on teamwork for the implementation of their ideas. ${ }^{13}$

\subsection{Cross-sectional Predictions}

In this section I extend the model to consider variations across technological areas. The extension considers $J$ unit circles of knowledge in place of a single circle. I assume that

\footnotetext{
${ }^{12}$ The extended model in the Appendix gives this result an explicit "time" interpretation, showing that the duration of education is increasing along the growth path.

${ }^{13} \mathrm{An}$ interesting extension considers the possibility that more narrowly educated individuals might have a narrower range of inspiration (smaller average $k$ ). I explore this extension formally in the Appendix and derive there a generalized condition for team size to increase as specialization increases. The intuition, which is shown clearly for a uniform distribution, is that team size will increase with specialization as long as the "reach" of innovators (the breadth of their creativity) does not decline as rapidly as their "grasp" (the breadth of their personal expertise).
} 
the elasticity parameters are the same across all areas of knowledge, while each circle has a specific depth of knowledge $D_{j}$ and a separate parameter $A_{j}$, which represents the relative productivity of knowledge in that area - whether the area is hot or cold. The structure of the model is as before, with two modifications. First, the difficulty of reaching the knowledge frontier will differ across technological areas. The educational cost for each area $j$ is:

$$
E_{i j}(\tau)=\left(b_{i j} D_{j}(\tau)\right)^{\varepsilon}
$$

Second, an innovator's productivity will depend on the characteristics of the technological area. I redefine $\theta$ as

$$
\theta_{i j}(t)=A_{j}(t) X(t)^{\chi} L_{j}\left(t, s_{i j}\right)^{-\sigma} b_{i j}^{\beta}
$$

This specification differs in two ways from that in equation (9). First, the congestion effects are now specific to the particular technological area, which is indicated by adding the subscript $j$ to $L\left(t, s_{i}\right)$. Second, I add the new parameter, $A_{j}(t)$, to indicate sector specific research opportunities. Innovators' inspirations are drawn from a distribution $F_{j}\left[s_{i j}, s_{i j}+1\right]$, so that all ideas from an innovator operating in area $j$ are implementable using expertise within that circle of knowledge.

The innovator's maximization problem is solved just as in Section 2.5, only we now consider the choice problem within a particular area of knowledge $j$. This generalized model results in a simple generalization of Proposition 1.

Proposition 3 Innovators choose a pair $\left(s_{i j}, b_{i j}\right)$ and a circle $j$ such that

(i) $L_{j}\left(t, s_{i j}\right)=L_{j}(t)$

(ii) $E^{*} / U^{*}=$ constant

(iii) $b_{i j}^{*}(\tau)=b_{j}^{*}(\tau)$

The results of Proposition 3 follow the same logic as Proposition 1. Innovators spread out to avoid duplicating each other. They choose their breadth of expertise such that educational expenditure and lifetime income are in constant ratio. Result (iii) and the central cross-sectional implications follow directly from this latter property. 
Corollary 2 The equilibrium implies that for any cohort $\tau$

(i) $E_{i j}^{*}(\tau)=E^{*}(\tau) \forall i, j$

(ii) $b_{j}^{*}(\tau)<b_{j^{\prime}}^{*}(\tau)$ iff $D_{j}(\tau)>D_{j^{\prime}}(\tau)$

(iii) $\overline{\operatorname{team}}_{j}(\tau)>\overline{\operatorname{team}}_{j^{\prime}}(\tau)$ iff $D_{j}(\tau)>D_{j^{\prime}}(\tau)$

The first result says that innovators will choose the same amount of education across sectors, regardless of differences in the depth of knowledge or innovation opportunities. This result is perhaps surprising, but the intuition is straightforward. Innovators allocate themselves across sectors so that differences in the degree of congestion will offset the variation in technological opportunities or educational burden. Once income is equated across sectors, innovators acquire the same total education because their optimal amount of education is a constant fraction of their expected income. The model thus makes the interesting dual prediction that successive cohorts of innovators will choose an increasing amount of education, while a given innovator cohort will choose an identical amount of education across widely different sectors.

In contrast, while we expect no variation in the level of education across sectors, we do expect differences in specialization and teamwork. Given that total educational attainment will be the same across sectors, those sectors with deeper knowledge must consequently see narrower expertise (Corollary 2.ii). In consequence, team size will be greater where the depth of knowledge is greater (Corollary 2.iii).

\section{Econometric Evidence}

Sections 2.7 and 2.8 motivate a number of investigations. The goal of the empirical work is descriptive: to examine a range of first-order facts that, together, shed light on these predictions and the model's underlying parameters. Using an augmented patent data set, we will be able to examine four outcomes in particular:

1. Team size

2. Age at first innovation

3. Specialization, and

4. The time lag between innovations 
The data is described in the following subsection. An investigation of basic time trends and cross-sectional results follow. Section 4 will consider interpretations of the new results as a whole and relate them to existing facts about innovation and growth. Together they paint a multi-dimensional picture that is consistent with a rapidly increasing burden of knowledge.

\subsection{Data}

I make extensive use of a patent data set put together by Hall, Jaffe, and Trajtenberg (Hall et al. 2001). This data set contains every utility patent issued by the United States Patent and Trademark Office (USPTO) between 1963 and 1999. The available information for each patent includes: (i) the grant date and application year, and (ii) the technological category. The technological category is provided at various levels of abstraction: a 414 main patent class definition used by the USPTO as well as more organized 36-category and 6-category measures created by Hall et al. (The 36-category and 6-category measures are described in Table 6.) For patents granted after 1975, the data set includes additionally: (iii) every patent citation made by each patent, and (iv) the names and addresses of the inventors listed with each patent. There are 2.9 million patents in the entire data set, with 2.1 million patents in the 1975-1999 period. See Figure 3.

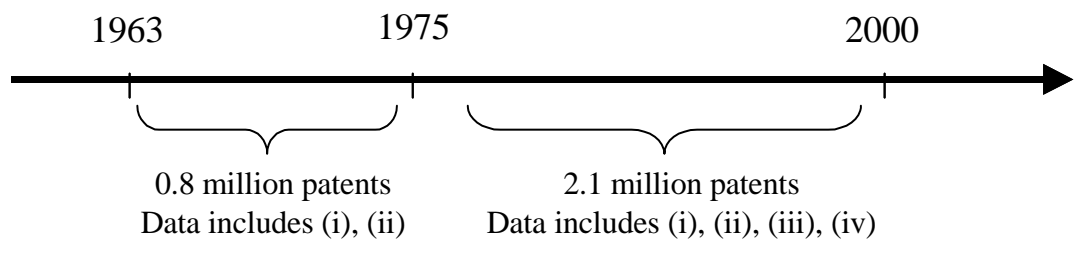

Figure 3: Summary of Available Data

Using the data available over the 1975-1999 time period, we can define two useful measures directly:

- Team Size. The number of inventors listed with each patent.

- Time Lag. The delay between consecutive patent applications from the same inventor.

For the latter measure, we identify inventors by their last name, first name, and middle initial and then build detailed patent histories for each individual.

We can also define two more approximate measures that will be useful for analysis: 
- Tree Size. The size of the citations "tree" behind any patent. Any given patent will cite a number of other patents, which will in turn cite further patents, and so on. For the purposes of cross-sectional analysis, the number of nodes in a patent's backwards-looking patent tree serves as a proxy measure for the amount of underlying knowledge.

- Field Jump. The probability that an innovator switches technological areas between consecutive patent applications. This can serve as a proxy measure for the specialization of innovators. The more specialized you are, the less capable you are of switching fields.

A limitation of this last measure is that, since technological categories are assigned to patents and not to innovators, inferring an innovator's specific field of expertise is difficult when innovators work in teams. For inventors who work in teams, the relation between specialization and field jump is in fact ambiguous: as inventors become more specialized and work in larger teams, they may jump as regularly as they did before. For the specialization analysis we will therefore focus on solo inventors, for whom increased specialization is always associated with a decreased capability of switching fields.

Finally, we would like to investigate the age at first innovation. Unfortunately, inventors' dates of birth are not available in the data set, nor from the USPTO generally. However, using name and zip code information it was possible to attain birth date information for a large subset of inventors through a public website, www.AnyBirthday.com. AnyBirthday.com uses public records and contains birth date information for 135 million Americans. The website requires a name and zip code to produce a match. Using a java program to repeatedly query the website, it was found that, of the 224,152 inventors for whom the patent data included a zip code, AnyBirthday.com produced a unique match in 56,281 cases. The age data subset and associated selection issues are discussed in detail in the Data Appendix. The analysis there shows that the age subset is not a random sample of the overall innovator population. This caveat should be kept in mind when examining the age results, although it is mitigated by the fact that the differences between the groups become small when explained by other observables, controlling for these observables in the age regressions has little effect, and the results for team size, specialization and time lag persist when looking in the age subset. See the discussion in the Data Appendix. 


\subsection{Time series results}

I consider the evolution over time of our four outcomes of interest. Figure 1 presents the basic data while Tables 2 through 5 examine the time trends in more detail.

Consider team size first. The upper left panel of Figure 1 shows that team size is increasing at a rapid rate, rising from an average of 1.70 in 1975 to 2.25 at the end of the period, for a $32 \%$ increase overall. Table 2 explores this trend further by performing regressions relating team size to application year, and we see that the time trend is robust to a number of controls. Controlling for compositional effects shows that any trends into certain technological categories or towards patents from abroad have little effect. Repeating the regressions separately for patents from domestic versus foreign sources shows that the domestic trend is steeper, though team size is rising substantially regardless of source. Repeating the time trend regression individually for each of the 36 different technological categories defined by Hall et al. shows that the upward trend in team size is positive and highly significant in every single technological category. Running the regressions separately by "assignee code" to control for the type of institution that owns the patent rights shows that the upward trend also prevails in each of the seven ownership categories identified in the data, indicating that the trend is robust across corporate, government, and other research settings, both in the U.S. and abroad. ${ }^{14}$ In short, we find an upward trend in team size that is both general and remarkably steep.

Next consider the age at first innovation. Note that we define an innovator's "first" innovation as the first time they appear in the data set. Since we cannot witness individuals' patents before 1975, this definition is dubious for (i) older individuals, and (ii) observations of "first" innovations that occur close to 1975. To deal with these two problems, I will limit the analysis to those people who appear for the first time in the data set between the ages of 25 and 35 and after 1985. The upper right panel of Figure 1 plots the average age over time, where we see a strong upward trend. The basic time trend in Table 3 shows an average increase in age at a rate of 0.66 years per decade. Controlling for compositional biases due to shifts in technological fields or team size has no effect on the estimates. The results are also similar when looking at different age windows. ${ }^{15}$ Analysis of trends within

\footnotetext{
${ }^{14}$ Table A.2 describes the ownership assignment categories.

${ }^{15}$ The table reports results for the 23 to 33 age window as well. In results not reported, I find that the trend is similar across subsets of these windows: ages 23-28, 25-30, 31-35, et cetera. Furthermore, there is no upward trend when looking at age windows beginning at age 35 .
} 
technological categories shows that the upward trend in age is quite general. Smaller sample sizes tend to reduce significance when the data is finely cut, but an upward age trend is found in all 6 technology classes using Hall et al's 6-category measure, and in 29 of 36 categories when using their 36-category measure. The upward age trend also persists across all patent ownership classifications.

Now we turn to specialization. The specialization measure considers the probability that an innovator switches fields between consecutive innovations. Before looking at the raw data, it is necessary to consider a truncation problem that may bias us toward finding increased specialization over time. The limited window of our observations (1975-1999) means that the maximum possible time lag between consecutive patents by an innovator is largest in 1975 and smallest in 1999. This introduces a downward bias over time in the lag between innovations. It is intuitive, and it turns out in the data, that people are more likely to jump fields the longer they go between innovations. ${ }^{16}$ Mechanically shorter lags as we move closer to 1999 can therefore produce an apparent increase in specialization. To combat this problem, I make use of a conservative and transparent strategy. I restrict the analysis to a subset of the data that contains only consecutive innovations which were made within the same window of time. In particular, we will look only at consecutive innovations when the second application comes within 3 years of the first. Furthermore, we will look only at innovations which were granted within 3 years of the application. ${ }^{17}$ This strategy eliminates the bias problem at the cost of limiting our data analysis to the 1975-1993 period and making our results applicable only to the sub-sample of "faster" innovators. ${ }^{18}$ The lower right panel of Figure 1 shows the trend from 1975-1993.

Table 4 considers the trend in specialization with and without this corrective strategy. The results there, together with the graphical presentation in Figure 1, indicate a smooth

\footnotetext{
${ }^{16}$ An interpretation consistent with the spirit of the model is that people need time to reeducate themselves when they jump fields, hence a field jump is associated with a larger time lag.

${ }^{17}$ Looking only at patents where the second application came within 3 years limits our analysis to those cases where the first application was made before 1997. However, a second issue is that patents are granted with a delay -2 years on average - and only patents that have been granted appear in the data. For a first patent applied for in 1996, it is therefore much more likely that we will witness a second patent applied for in 1997 than one applied for in 1999 - introducing further downward bias in the data. To deal completely with the truncation problem, we will therefore further limit ourselves to patents which were granted within 3 years of their application, which means that we will only look at the period 1975-1993.

${ }^{18}$ These restrictions maintain a significant percentage of the original sample. For example, of the 111,832 people who applied successfully for patents in 1975, 81,955 of them received a second patent prior to 2000 . Of these 81,955 people for whom we can witness a time lag between applications, $79.8 \%$ made their next application within three years. Of those, $88.5 \%$ were granted both patents within three years of application.
} 
decrease in the probability of switching fields. The decline is again quite steep. Using the central estimate for the trend of -..003, we can interpret a $6 \%$ increase in specialization every ten years. Note that our main results, and Figure 1, use the 414-category measure for technology to determine whether a field switch has occurred. This is our most accurate measure of technological field (Hall et al.'s measures are aggregations of it), but the results are not influenced by the choice of field measure. Note in particular that the percentage trend is robust to the choice of the 6,36 , or 414 category measure for technology - the trend is approximately $6 \%$ per decade for all three. Including controls for U.S. patents, the application time lag, ownership status, and the technological class of the initial patent has little effect. Furthermore, looking for trends within each of Hall et al.'s 36 categories, we find that the probability of switching fields is declining in 34 of the 36 ; the decline is statistically significant in 20 . In sum, we see a robust and strongly decreasing tendency for solo innovators to switch fields.

Finally, I consider the time lag between an innovator's innovations. The truncation bias in the time lag described above, which had little effect with specialization, is of course crucial here, so we employ the same corrective strategy and look only at the 1975-1993 period and the sub-sample of "faster" innovators. The lower left panel of Figure 1 presents the data graphically and Table 5 considers the trend with and without various controls. The regressions show a mild upward trend, but this should be viewed skeptically given the clearly cyclical behavior we see in the graph. Considering the coefficients on various controls, we see that bigger teams innovate faster and that part of the mild upward trend is accounted for by a composition effect - innovators switching into fields where the delay is longer. What is most interesting about the time lag data becomes apparent only when we look at trends within technological categories. Here we find a richer story: Most fields (19 of 36) show a significant decrease in the average lag between innovations. A smaller number (11 of 36) show a significant increase. ${ }^{19}$ Overall, I conclude that the average time lag between an innovator's patent applications, unlike the other outcomes of interest, shows no decisive trend; rather, trends in time lags are cycling and differ strongly across

\footnotetext{
${ }^{19}$ The fact that the overall trend is upward indicates that this group of 11 is pulling relatively strongly. Upon closer examination we find that the heavyweights among these eleven are Organic Compounds (\#14), Drugs (\#31), and Biotechnology (\#33) - all areas related to the pharmaceutical industry. This result is consistent with Henderson \& Cockburn's (1996) finding that researchers in the pharmaceutical industry are having a greater difficulty in producing innovations over time.
} 
technological areas.

\subsection{Cross-section results}

For a first look at the data in cross-section, Table 6 presents a simple comparison of means across the 6 and 36 technological categories of Hall et al (2001). The middle column in the table presents the mean age at first innovation, and the data shows a remarkable consistency across technological categories. In 30 of the 36 categories, an innovator's first innovation tends to come at age 29. The lowest mean age among the 36 categories is 28.8 , and the highest is 31.1, though this last relies on only 12 observations and is an outlier with regard to the others. The table shows that regardless of whether the invention comes in "Nuclear \& X-rays", "Furniture, House Fixtures", "Organic Compounds", or "Information Storage", the mean age at first innovation is nearly the same. According to the cross-sectional variation of the model, this is what we would expect. Given income arbitrage, innovators expand their breadth of expertise in shallow areas of knowledge and focus their breadth of knowledge in deep areas of knowledge so that their educational investment does not differ across fields. ${ }^{20}$

The next columns of the table consider the average team size. Here we see large differences across technological areas. The largest average team size, 2.90 for the "Drugs" subcategory, is over twice that of the smallest, 1.41 for the "Amusement Devices" subcategory.

Finally, the last columns of the table consider the probability that a solo innovator will switch sub-categories between innovations. Here, as with team size and unlike the age at first innovation, we see large differences across technological areas. This variation is again consistent with the predictions of the model. At the same time, this basic, cross-sectional variation in the probability of field jump is difficult to interpret: the probability of field jump will be tied to how broadly a technological category happens to be defined, which may vary to a large degree across categories.

I can go further by using a direct measure of the quantity of knowledge underlying a patent. In particular, I can analyze in cross-section what an increase in the knowledge

\footnotetext{
${ }^{20}$ These results can also be considered in a regression format. Pooling cross-sections and using application year dummies to take care of trends, the results are extremely similar. One can also adjust the time at first innovation by subtracting category-specific estimates of the time lag to get a closer estimate of an individual's education. One can also look at different age windows. The result that ages are nearly identical across fields is highly robust.
} 
measure implies for our outcomes of interest.

For a continuous measure of the quantity of knowledge I will use the logarithm of the number of nodes (i.e., patents) in the citation "tree" behind any patent. ${ }^{21}$ As usual, there is a truncation issue that needs to be considered: the data set does not contain citation information for patents issued before 1975, so we tend to see the recent part of the tree. The measure of underlying knowledge is then noisier the closer we are to 1975, and I will therefore focus on cross-sections later in the time period. A second issue is that the average tree size and its variance grow extremely rapidly in the time window, which makes it difficult to compare data across cross-sections without a normalized measure. Two obvious normalizations are: (1) a dummy for whether the tree size is greater than the withinperiod median; (2) the difference from the within-period mean tree size, normalized by the within-period standard deviation. Results are reported using the latter definition, as it is informationally richer, though either method shows similar results.

Table 7 examines the relationship between team size and tree size in pooled crosssections, with and without various controls. I add a quadratic term for the variation in team size to help capture evident curvature, and we see that team size rises at an increasing rate as the measure of knowledge depth increases. For innovations with larger citation trees, the rise in team size is particularly strong. With very deep knowledge trees, an increase of one standard deviation in the tree size is associated with an average increase in team size of one person. The table shows that the cross-sectional relationship holds for domestic and foreign-source patents and when controlling for technological category, so that the variation appears both within fields and across them. Technological controls are perhaps best left out, however, since the variations in mean tree size across technological category may be equally of interest. Finally, we might be concerned that bigger teams simply have a greater propensity to cite, which results in larger trees. This concern proves unwarranted. Controlling for the variation in the direct citations made by each patent, we

\footnotetext{
${ }^{21}$ The distribution of the raw node count within cross-section is highly skewed - the mean is far above the median, so that upper tail outliers can dominate the analysis. I therefore use the natural log of the node count, which serves to contain the upper tail. A (loose) theoretical justification is knowledge depreciation: distant layers of the tree are less relevant to a patent than nearer layers, so there is a natural diminishing impact as nodes grow more distant. The diminishing impact of the large, distant layers, which dominate the node counts, is captured loosely by taking logs. Noting that the basic results are similar when we use the median-based measure of knowledge depth (a dummy for whether the raw node count is above or below the median, which is independent of any monotonic transform of the node count) we can be reasonably comfortable with the log measure.
} 
find that relationship actually strengthens. In fact, we see that bigger teams tend to cite less. This result gives us greater faith in the causative arrow implied by the regressions.

Next we turn to the age at first innovation. Table 8 examines, in pooled cross-sections, the relationship between age and knowledge for those individuals for whom we can be confident that they are innovating for the first time (see discussion above). The general conclusion from the table is that we must work hard to find a relationship, and at its largest it is very small. It is not robust to the specific age window, is reduced when controlling for the technological category, and disappears when controlling for the number of direct citations made. Taking a coefficient of 0.1 as the maximum estimate from the table, we find that an increase of one standard deviation in the knowledge measure leads to a 0.1 year increase in age. This coefficient may be attenuated given that our proxy measure of knowledge is, at best, noisy, but I conclude that there is at most only a weak relationship between the amount of knowledge underlying a patent and the age at first innovation.

Finally, Table 9 considers the relationship between the probability of field jump and the knowledge measure. The table shows a robust negative relationship: solo innovators are less likely to jump fields when their initial patent has a larger node count. If we identify a larger node count with a deeper area of knowledge, then this negative correlation is again consistent with the predictions of the model. However, I place less emphasis on this result. The fact that the node count captures the recent part of the tree means that the measure is likely correlated not just with the total underlying knowledge but also with the recent ease of innovation. This effect could also explain the negative correlation. Innovators will be less likely to leave a fruitful area, which will be registered as a decreased probability of jumping fields.

\section{Discussion}

This paper is built on two observations. First, innovators are not born at the frontier of knowledge but must initially undertake significant education. Second, the distance to the frontier shifts over time. I investigate equilibrium implications of these two observations and then test these implications empirically. In this section I will review the results and consider them further in light of existing literatures. Two suggestive conclusions are drawn. First, human capital decisions appear first-order in understanding important variations in 
innovative activity across fields and over time. Second, a subset of the evidence points to a rising burden of knowledge.

The empirical work of Section 3 produces six key facts. We find that the age at first innovation is increasing over time while it shows no variation across widely different fields, as demanded by the theory. Meanwhile, team size and specialization are increasing over time and varying across fields, with greater teamwork and specialization the larger a measure for the amount of underlying knowledge. These time-series and cross-sectional patterns are all robust to many controls. The upward trends in age, teamwork, and specialization are robust across widely different technological areas and research environments. The upward trends in teamwork and specialization are also especially steep: teamwork is increasing by $17 \%$ per decade and the specialization measure by $6 \%$ per decade.

Interestingly, some similar trends have been documented elsewhere - and in research environments outside of patenting. The age at which individuals complete their doctorates rose generally across all major fields from 1967-1986, with the increase explained by longer periods in the doctoral program (National Research Council, 1990). The duration of doctorates as well as the frequency of post-doctorates has been rising across the life-sciences since the 1960s (Tilghman et al, 1998). An upward age trend has also been noted among the great inventors of the 20th Century at the age of their noted achievement (Jones, 2005), as shown in Table 1. Meanwhile, like the general trends in innovator teamwork documented here, upward trends in academic coauthorship have been documented in many academic literatures, including physics and biology (Zuckerman \& Merton, 1973), chemistry (Cronin et al, 2004), mathematics (Grossman, 2002), psychology (Cronin et al, 2003), and economics (McDowell \& Melvin, 1983; Hudson, 1996; Laband \& Tollison, 2000). These coauthorship studies show consistent and, collectively, general upward trends, with some of the data sets going back as far as 1900 .

The burden of knowledge mechanism can also speak to trends in the data aggregates currently debated in the growth literature. First of all, as indicated in Section 2.6, an increasing burden of knowledge provides one explanation for why high growth rates in the number of R\&D workers have not led to increases in rates of TFP growth. Of further interest is the drop in total patent production per total researchers, which has been documented across a range of countries and industries and may go back as far as 1900 and even before (Machlup 1962). Certainly, not all researchers are engaging in patentable activities, and 
it is possible that much of this trend is explained by relatively rapid growth of research in basic science. $^{22}$ However, the results here indicate that among those specific individuals who produce patentable innovations, the ratio of patents to individuals is in fact declining. In particular, the recent drop in patents per U.S. R\&D worker, a drop of about $50 \%$ since 1975 (see Segerstrom 1998), is roughly consistent in magnitude with the rise in team size over that period. With the time lag between innovations showing little if any deterministic trend, we have a simple explanation for where these extra innovators have recently been going - into bigger teams.

In all, the micro-evidence presented in this paper, together with other available microevidence and the aggregate data trends cited above, suggest general and multi-dimensional patterns that may all be understood within the knowledge burden model. While any individual piece of evidence could be explained by other means, the burden of knowledge model knits together a wide range of evidence within a single framework. Thinking carefully about the human capital investments faced by innovators leads to precise and empirically relevant cross-sectional and dynamic insights. Moreover, while the model has relevant organizational and growth implications regardless of whether the burden of knowledge rises or falls with time, the evidence suggests specifically that the burden of knowledge is increasing. The model delivers this inference directly through increasing specialization and teamwork, but note further that a combination of greater specialization and greater educational attainment is especially difficult to reconcile without appealing to a greater knowledge burden. If innovators are becoming more specialized but the distance to the frontier is not increasing, then innovators should have required less education over time.

As emphasized in the model, the knowledge burden channel is not dispositive of other mechanisms, which operate independently and may also be important to innovator output. The general equilibrium setting of the model explicitly embraces popular stories in the literature regarding innovation exhaustion ("fishing out" stories), increasing innovation potential, and market size effects. Fishing-out stories are particularly interesting because they can provide an alternative or additional explanation for the data aggregates - patterns which have motivated that literature. While the trends in the data regarding team size, age, or specialization appear orthogonal to a fishing-out story, this orthogonality leaves room

\footnotetext{
${ }^{22}$ Such an explanation could be inferred from the observations of Mokyr (1990), for example, who sees an increasing role for basic science as a foundation for technological advance.
} 
for a fishing-out mechanism alongside a rising burden of knowledge when one confronts aggregate data. $^{23}$ Defining precise micro-data tests for a fishing-out story is a challenge for future research. Differentiating between a fishing-out and knowledge burden mechanism is challenging on the basis of productivity alone, as any decrease in the size or rate of innovations can be explained by either narrowing expertise or innovation exhaustion.

If a rising burden of knowledge is an inevitable by-product of technological progress, then the model indicates pessimistic predictions for long-run growth. However, there are two kinds of escapes worth noting. First, as discussed in Section 2.6, if the value of knowledge increases sufficiently rapidly in Newton's original sense of "seeing farther" (i.e. $\chi$ is large), then the output of individual innovators may be sufficient, despite a rising educational burden, to sustain growth without increasing effort. While the 20th century's aggregate data patterns - rapidly increasing R\&D effort but flat TFP growth - do not lead to such optimistic conclusions about the current balance of forces, there is nothing to say that this balance can't shift in the future.

Second, even if the stock of knowledge is accumulating over long periods of time, it may be that some future revolution in science can reset and simplify the knowledge space, causing a fall in the burden of knowledge $(D(t)$ falls). Scientific revolutions - Kuhnian "paradigm" shifts - might therefore have significant benefits by easing the inter-generational transmission of knowledge. Related to this point, the efficiency of education - the rate at which we transfer knowledge from one generation to the next - becomes a policy parameter with first-order implications for the ultimate organization of innovative activity and for growth. Future improvements in the knowledge transfer rate could potentially overcome growth in the knowledge stock. While this transfer rate probably faces physiological limits, policy choices in education take on further importance, as policy features from teacher pay to curricular design and the need for a 'liberal arts' education all impact the rate at which human capital can be transferred to the young.

\footnotetext{
${ }^{23}$ The fact that increasing team size appears to explain recent declines in the ratio of aggregate patents per researcher, as discussed above, does bring that particular aggregate fact closer to the burden of knowledge explanation.
} 


\section{Appendix}

$$
\begin{aligned}
& \text { Proof of Proposition 1.i } \\
& \qquad L(t, s)=L_{R}(t) \forall s
\end{aligned}
$$

First I generalize the innovator's income function to allow the possibility that not all ideas are feasible to implement. Then I show that innovators will array themselves evenly around the circle.

(1) Define $p_{i}(t)$ such that $\forall k>p_{i}(t)$ the necessary teammates do not exist and $\forall k \leq p_{i}(t)$ the necessary teammates do exist. The probability that an idea $k$ is feasible is then $F\left(p_{i}(t)\right)$. The innovator's expected income at the time of their birth $t^{\prime}$ is a generalized version of $(5)$ that allows for the possibility that an idea is infeasible:

$$
b_{i}^{* \beta} \int_{t^{\prime}}^{\infty} F\left(p_{i}(t)\right) X(t)^{\chi} L\left(t, s^{\prime}\right)^{-\sigma} M(t) e^{-\phi\left(t-t^{\prime}\right)} d t-\left(b_{i}^{*} D\left(t^{\prime}\right)\right)^{\varepsilon}
$$

Note that, in any equilibrium, $b_{i}^{*}>0$ and $F\left(p_{i}(t)\right)>0$ by the arbitrage condition (12), since otherwise $U_{i}^{R \& D}=0$ but $U^{\text {wage }}>0$. Moreover, there must exist an arbitrarily small $\epsilon$ such that $0<\epsilon<b_{i}^{*}$.

(2) By contradiction, imagine that

$$
L\left(t, s^{\prime}\right)>L\left(t, s^{\prime \prime}\right)
$$

where $s^{\prime}>s^{\prime \prime}>s^{\prime}-\epsilon$. That is, there exist two neighboring points, a relatively crowded point $s^{\prime}$ and a less crowded point $s^{\prime \prime}$. Without loss of generality, choose individual $i$ at $s^{\prime}$ such that $b_{i}^{*} \leq b_{j}$ for some $j$ at $s^{\prime}, j \neq i$. If this individual $i$ at $s^{\prime}$ were to shift to $s^{\prime \prime}$, then the access to potential teammates remains unchanged. (The individual can always hire someone in $L\left(t^{\prime}, s^{\prime}\right)$ as a teammate, and everyone else at that point has weakly greater expertise.) Therefore $\widehat{p}_{i}(t)=p_{i}(t)+\epsilon$, and the probability that an idea $k$ is feasible is weakly increasing with this deviation since for any distribution function $F\left(p_{i}(t)+\epsilon\right) \geq F\left(p_{i}(t)\right.$.

Therefore, from (20) and the equilibrium condition (11), the choice $s^{\prime}$ (i.e. the crowded location) can only be an equilibrium for person $i$ if

$$
\int_{t^{\prime}}^{\infty} L\left(t, s^{\prime}\right)^{-\sigma} X(t)^{\chi} M(t) e^{-\phi\left(t-t^{\prime}\right)} d t \geq \int_{t^{\prime}}^{\infty} L\left(t, s^{\prime \prime}\right)^{-\sigma} X(t)^{\chi} M(t) e^{-\phi\left(t-t^{\prime}\right)} d t
$$

Given the continuity of $L$ with time, $L\left(t, s^{\prime}\right)>L\left(t, s^{\prime \prime}\right)$ for all $t$ in some interval $\left[t^{\prime}, t^{\prime \prime}\right]$. Therefore, the expected income to innovator $i$ in the interval $\left[t^{\prime}, t^{\prime \prime}\right]$ must be strictly less with the crowded choice $s^{\prime}$ then with the less crowded choice $s^{\prime \prime}$. Therefore, innovator $i$ must believe that

$$
\int_{t^{\prime \prime}}^{\infty} L\left(t, s^{\prime}\right)^{-\sigma} X(t)^{\chi} M(t) e^{-\phi\left(t-t^{\prime}\right)} d t>\int_{t^{\prime \prime}}^{\infty} L\left(t, s^{\prime \prime}\right)^{-\sigma} X(t)^{\chi} M(t) e^{-\phi\left(t-t^{\prime}\right)} d t
$$

That is, eventually the relatively crowded choice must produce greater income. But multiplying both sides of this expression by the constant $e^{-\phi\left(t^{\prime}-t^{\prime \prime}\right)}$, we see that in the subgame for those born at time $t^{\prime \prime}$ no person would choose $s^{\prime \prime}$. Hence $L\left(t^{\prime \prime}, s^{\prime \prime}\right)$ is not increasing, $L\left(t^{\prime \prime}, s^{\prime}\right)>L\left(t^{\prime \prime}, s^{\prime \prime}\right)$, and there is no finite $t^{\prime \prime}$ at which (22) holds. Hence (21) cannot hold. Hence, by contradiction, no such point $s^{\prime \prime}$ can exist and therefore there can be no points on the circle where the mass is less than any other point. QED. 
Proof of Proposition 1.ii

$$
E^{*}(\tau) / U^{*}(\tau)=\text { constant }
$$

Differentiate (14) with respect to $b_{i}$, producing the first order condition:

$$
\frac{\beta}{b_{i}^{*}} \int_{\tau}^{\infty} b_{i}^{* \beta} X(t)^{\chi} L_{R}(t)^{-\sigma} M(t) e^{-\phi(t-\tau)} d t=\frac{\varepsilon}{b_{i}^{*}}\left(b_{i}^{*} D(\tau)\right)^{\varepsilon}
$$

In other words, $\beta \int_{\tau}^{\infty} v^{*}(t) d t=\varepsilon E^{*}(\tau)$. Noting that $U^{*}(\tau)=\int_{\tau}^{\infty} v^{*}(t) d t-E^{*}(\tau)$, the first order condition is just $E^{*}(\tau) / U^{*}(\tau)=\varepsilon / \beta-1$, which is a constant. QED. (Note: An interior maximum requires $\varepsilon>\beta$. If this condition does not hold, then innovators will choose to learn all available knowledge, $b_{i}^{*}=1$. Such a corner solution can also emerge when $\beta<\varepsilon$ if the unique maximum described by (23) occurs where $b_{i}^{*}>1$. These cases, where the innovator learns all available knowledge, are less interesting and are left aside in further analysis.)

$$
\begin{aligned}
& \text { Proof of Proposition 1.iii } \\
& \qquad b_{i}^{*}=b^{*}(\tau)
\end{aligned}
$$

Given arbitrage in lifetime income (12), all innovators in the same cohort have identical $U^{*}(\tau)$. By Proposition 1.ii, $E^{*}(\tau) / U^{*}(\tau)$ is a constant, hence all innovators in a cohort have identical $E^{*}(\tau)$. From $(6), E^{*}(\tau)=\left(b_{i}^{*} D(\tau)\right)^{\varepsilon}$. Therefore, common $E^{*}(\tau)$ implies identical $b^{*}(\tau)$ for all innovators in the same cohort. QED.

\section{Proof of Proposition 2}

If $g$ is constant, we can take logs and differentiate (15) with respect to time to see that,

$$
g=g_{\bar{\theta}}+g_{L}
$$

To define $g_{\bar{\theta}}$, note first that the average productivity of innovators is the sum of the productivity of each cohort weighted by the fraction of that cohort in the population. ${ }^{24}$

$$
\bar{\theta}(t)=\int_{-\infty}^{t} \theta(\tau)\left(g_{L}+\phi\right) e^{\left(g_{L}+\phi\right)(\tau-t)} d \tau
$$

The growth rate of $\theta(\tau)$ with respect to $\tau$ is just $\beta g_{b^{*}}$, which is seen by taking logs of the definition of $\theta$ (equation (9)), using the equilibrium result $b_{i}=b^{*}(\tau)$, and differentiating with respect to $\tau$. We can therefore integrate $(25)$ to find that $\bar{\theta}(t)=$ $\theta(t)\left(g_{L}+\phi\right) /\left(\beta g_{b^{*}}+g_{L}+\phi\right)$. The steady-state growth rate in $\bar{\theta}(t)$ is therefore equivalent to the steady-state growth rate in $\theta(t)$, so that $g=g_{\bar{\theta}}+g_{L}=g_{\theta}+g_{L}$.

$\theta(t)$ is the productivity of the latest cohort of innovators at the time of their birth. Therefore $g_{\theta}$ is just $\chi g+\beta g_{b^{*}}-\sigma g_{L}$, which is seen by taking logs in the definition of $\theta(t)$, and differentiating with respect to $t$. Therefore,

\footnotetext{
${ }^{24}$ The size of a cohort at its birth is $\left(g_{L}+\phi\right) L(\tau)$, so the surviving size of that cohort at some time $t>\tau$ is $\left(g_{L}+\phi\right) L(\tau) e^{-\phi(t-\tau)}$, and the fraction of the population $L(t)$ who belong to that cohort is $\left(g_{L}+\phi\right) e^{-g_{L}(t-\tau)} e^{-\phi(t-\tau)}$.
} 


$$
g_{\bar{\theta}}=\chi g+\beta g_{b^{*}}-\sigma g_{L}
$$

Note that $E^{*} / U^{*}$ is constant (Proposition 1.ii), which implies $g_{E^{*}}=g_{U^{*}}$. Furthermore, from (13), $g_{U^{*}}=g$, which implies $g_{E^{*}}=g$. From (6), $g_{E^{*}}=1 / \varepsilon\left(g_{b^{*}}-g_{D}\right)$, and from (7), $g_{D}=\delta g$. Therefore $g_{b^{*}}=\left(\frac{1}{\varepsilon}-\delta\right) g$, a result presented in (17).

Inserting (17) into (26), the result into (24), and rearranging produces the expression for steady-state growth in equation (16). QED.

\section{Proof of Corollary 1.i}

$$
g_{E^{*}}=g
$$

$E^{*} / U^{*}$ is constant (Proposition 1.ii), which implies $g_{E^{*}}=g_{U^{*}}$. From (13), $g_{U^{*}}=g$. Therefore, $g_{E^{*}}=g$. QED

$$
\begin{gathered}
\text { Proof of Corollary 1.ii } \\
g_{b^{*}}<0 \text { iff } \delta>1 / \varepsilon
\end{gathered}
$$

The growth rate of $b^{*}$ is given in (??). Hence $g_{b^{*}}<0$ iff $\delta>1 / \varepsilon$. QED.

$$
\begin{aligned}
& \text { Proof of Corollary 1.iii } \\
& \overline{t e a m}(t)>0 \text { iff } \delta>1 / \varepsilon
\end{aligned}
$$

Recall that $k$, the breadth of expertise required to implement an idea, has a smooth distribution function $F(k)$. A cohort with breadth of expertise $b$ will therefore produce a team of size 1 with probability $F(b)$, a team of size 2 with probability $F(2 b)-F(b)$, and so on. Recall also that teams are formed within cohorts if possible and with the minimum possible number of individuals (see Section 2.4). Since individuals allocate themselves evenly around the circle in any cohort (Proposition 1.i), any necessary teammates are always available within one's own cohort. This implies that teams are formed from individuals with identical choices of $b, b^{*}(\tau)$ (Proposition 1.iii). Since teams are formed from the minimum number of individuals, the implementation of any idea $k$ requires $\lceil(k / b)$ team members; that is, $k / b$ rounded up to the nearest integer. The maximum team size in a cohort with breadth of expertise $b$ is defined by $n=\lceil(1 / b)$. The expected team size is $\overline{\text { team }}(b)=1 F(b)+2(F(2 b)-F(b))+\ldots+n(1-F((n-1) b)$. Collecting terms in this expression, $\overline{\text { team }}(b)=n-\sum_{j=1}^{n-1} F(j b)$ where $j$ indexes a particular realization of team size. Differentiating with respect to $b$ shows that, $d \overline{\text { team }}(b) / d b=-\sum_{j=1}^{n-1} j f(j b)$ where $f(k)=d F / d k$ is the probability density function corresponding to $F$. Given that a density function is weakly positive at any point, we see that team size is weakly increasing as $b$ falls. Hence the conditions for average team size to increase with time are identical to the condition for expertise to narrow; i.e. if and only if $\delta>1 / \varepsilon$. QED. 


\section{Extension to Corollary 1.iii}

A generalized condition for team size to increase with specialization

I explore here the evolution of team size when the distribution of $k$ changes with an individual's breadth of expertise, $b$. Define the generalized distribution function by $F(k ; b)$ and the corresponding density function as $f(k ; b)=d F(k ; b) / d k$. The average team size for a cohort with breadth of expertise $b$ is derived just as in (??),

$$
\overline{\operatorname{team}}(b)=n-\sum_{j=1}^{n-1} F(j b ; b)
$$

Noting that $F(j b ; b)=\int_{0}^{j b} f(k ; b) d k$, we can use Leibniz's rule to differentiate $(27)$ with respect to $b$ and thereby define a necessary and sufficient condition for team size to increase with specialization:

$$
\sum_{j=1}^{n-1}\left(\int_{0}^{j b} \frac{d f(k ; b)}{d b} d k+j f(j b ; b)\right)>0 \Leftrightarrow \frac{d \overline{\operatorname{team}}(b)}{d b}<0
$$

The second term on the left hand side is recognized from equation (??) and acts to make team size increase with specialization. The effect of the first term is ambiguous, however, so that the effect of specialization on team size cannot be signed without considering distribution-specific properties.

We can gain some intuition for this condition by considering the simple case where $k$ is drawn from a uniform distribution. Specifically, let $k \sim U\left[0, b^{\alpha}\right]$, so that $f(k ; b)=b^{-\alpha}$. Using (28), it is then straightforward to show that $\alpha<1 \Leftrightarrow d \overline{\text { team }}(b) / d b<0$. Noting that the mean of $k$ is $E(k)=\frac{1}{2} b^{\alpha}$, it is also straightforward to show that $\alpha$ is the elasticity of $E(k)$ with respect to $b$. Therefore, we see that team size will be increasing with specialization so long as the elasticity of $E(k)$ with respect to expertise is less than 1 . In other words, team size will be increasing as long as innovators' average "reach", given by $E(k)$, does not decline faster than their average "grasp", given by $b$.

\section{Proof of Proposition 3}

The proof follows exactly the same structure as the proof of Proposition 1 and is omitted for brevity.

$$
\begin{gathered}
\text { Proof of Corollary 2.i } \\
E_{i j}^{*}(\tau)=E^{*}(\tau) \forall i, j
\end{gathered}
$$

Arbitrage implies a common $U^{*}(\tau)$ within every cohort. Since $E^{*}(\tau) / U^{*}(\tau)$ is a constant (Proposition 3.ii), every innovator must choose the same $E^{*}(\tau)$. QED.

Proof of Corollary 2.ii

$$
b_{j}^{*}(\tau)<b_{j^{\prime}}^{*}(\tau) \text { iff } D_{j}(\tau)>D_{j^{\prime}}(\tau)
$$


All innovators in a cohort, by Corollary 2.i, choose the same amount of education, $E^{*}(\tau)=\left(b_{j}^{*}(\tau) D_{j}(\tau)\right)^{\varepsilon}$. Therefore $b_{j}^{*}(\tau) D_{j}(\tau)=b_{j^{\prime}}^{*}(\tau) D_{j^{\prime}}(\tau) \forall j, j^{\prime}$ and hence the corollary 2.ii. QED.

$$
\begin{gathered}
\text { Proof of Corollary 2.iii } \\
\overline{\operatorname{team}}_{j}(\tau)>\overline{\text { team }}_{j^{\prime}}(\tau) \text { iff } D_{j}(\tau)>D_{j^{\prime}}(\tau)
\end{gathered}
$$

By Corollary 2.ii, an innovator cohort within a circle of knowledge $j$ will have narrower expertise the greater the depth of knowledge. By the same logic as in the proof of Corollary 1.iii, narrower expertise is associated with larger team size. QED

\section{Extended Model: A Time Cost to Education}

The following model is a generalization of the model in the text. The model in the text allows for an additively separable cost of education, $E$, where this cost can be thought of as either an out-of-pocket expense or a direct utility cost of effort. Here I will introduce an additional opportunity cost of education: choosing more education results in a longer period at the beginning of life when one does not earn income. In particular, define $T=\alpha \ln (b D)$ as the duration of education., which is monotonically increasing in the amount of knowledge learned, $b D$. The model is as before, except innovator income is defined by

$$
U_{i}^{R \& D}(\tau)=\int_{\tau+T}^{\infty} v_{i}(t) e^{-\phi(t-\tau)} d t-E_{i}(\tau)
$$

in place of (5).

Equilibrium analysis follows mostly as before. The equilibrium choice of $s$ still requires that innovators spread out evenly around the circle. The equilibrium choice of $b_{i}^{*}$ becomes analytically more tedious, as the choice of breadth of expertise now additionally affects one limit of the integral in (29). Using Leibniz's rule in differentiating (29), in addition to the definitions of $v$ and $E$ in (10) and (6), we can write the first-order condition for the choice of $b$, with some manipulation, as:

$$
\beta-\varepsilon \frac{E^{*}(\tau)}{\Pi^{*}(\tau)}=b_{i}^{*} \frac{\partial T}{\partial b_{i}^{*}} \frac{v_{i}^{*}(\tau+T) e^{-\phi T^{*}}}{\Pi^{*}(\tau)}
$$

where $\Pi(\tau) \equiv \int_{\tau+T}^{\infty} v_{i}(t) e^{-\phi(t-\tau)} d t$. This is a generalization of $(23)$ - the simpler case with no time-cost, where the right hand side of $(30)$ is zero $(\partial T / \partial b=0)$. Here, given the definition of $T, b_{i}^{*} \partial T / \partial b_{i}^{*}=\alpha$. To analyze $v_{i}^{*}(\tau+T) e^{-\phi T^{*}} / \Pi^{*}(\tau)$, we will proceed by focusing on the equilibrium along a balanced-growth path. On the balanced growth path, $X$ grows at rate $g$, while $L_{R}$ and $M$ grow at rate $g_{L}$. Under these conditions, it is easily shown that $v_{i}^{*}(\tau+T) e^{-\phi T^{*}} / \Pi^{*}(\tau)=\phi+\chi g+(\sigma-1) g_{L}$. Therefore, $E^{*}(\tau) / \Pi^{*}(\tau)=$ $\beta / \varepsilon-(\alpha / \varepsilon)\left(\phi+\chi g+(\sigma-1) g_{L}\right)$. Noting that $U^{*}(\tau)=\Pi^{*}(\tau)-E^{*}(\tau)$, we have the result

$$
E^{*}(\tau) / U^{*}(\tau)=\text { constant }
$$


In other words, we have the same result as Proposition 1.ii (with the exception that we are now focusing on the steady-state growth path), from which Proposition 1.iii, Proposition 3 , and Corollaries 1 and 2 will follow. Since both $E$ and $T$ are monotonically increasing in the amount of knowledge learned $(b D)$, rising $E^{*}$ along the growth path (Corollary 1.i) implies that $T^{*}$, the duration of education, also rises along the growth path. Similarly, common $E^{*}$ across fields (Corollary 2.i) implies that $T^{*}$ is the same across fields.

The one set of results that must be generalized is Proposition 2, which defines the steady-state growth rate. The steady-state growth rate is now an implicit function of the model parameters. (The derivation follows along the lines of the proof of Proposition 2). In the special case that $\alpha=0$, so that there is no time-cost to education, the steady-state growth is given by (16), as before. In the special case where specialization doesn't change with time $(\varepsilon=1 / \delta)$, the growth rate is given by

$$
g=\frac{1-\sigma}{1-\chi+\alpha / \varepsilon\left(\phi+g_{L}\right)} g_{L}
$$

Here the effect of the burden of knowledge on growth is felt entirely through the time cost of education. Larger values of the parameter $\alpha$, which implies a higher sensitivity of educational duration to the amount of knowledge one learns, causes lower growth rates, since one spends a smaller portion of the one's life-cycle actively producing innovations.

\section{Data Appendix}

The reader is referred to Hall et al (2001) for a detailed discussion of their patent data set. This appendix focuses on the age information collected to augment the Hall et al data.

Age data was collected using the website www.AnyBirthday.com, which requires a name and zip code to produce a match. As is seen in Table A.1, 30\% of U.S. inventors listed a zip code on at least one of their patent applications, and of these inventors AnyBirthday.com produced a birth date in $25 \%$ of the cases. While the number of observations produced by AnyBirthday.com is large, it represents only 7.5\% of U.S. inventors. This Appendix explores the causes and implications of this selection. The first question is why zip code information is available for only certain inventors. The second question is why AnyBirthday.com produces a match only one-quarter of the time. The third question is whether this selection appears to matter.

Table A.2 compares how patent rights are assigned across samples. The table shows clearly that zip code information is virtually always supplied when the inventor has yet to assign the rights; conversely, zip code information is never provided when the rights are already assigned. Patent rights are usually assigned to private corporations (80\% of the time) and remain unassigned in the majority of the other cases (17\% of the time). An unassigned patent indicates only that the inventor(s) have not yet assigned the patent at the time it is granted. Presumably, innovators who provide zip codes are operating outside of binding contracts with corporations, universities, or other agencies that would automatically acquire any patent rights. The zip-code subset is therefore not a random sample, but is capturing a distinct subset of innovators who, at least at one point, were operating independently. Despite this distinction, this subset may not be substantially 
different from other innovators: the last column of Table A.2 indicates that, when looking at the other patents produced by these innovators, they have a similar propensity to assign them to corporations as the U.S. population average.

The nature of the selection introduced by AnyBirthday.com is more difficult to identify. The website reports a database of 135 million individuals and reports to have built its database using "public records". Access to public records is a contentious legal issue. ${ }^{25}$ Public disclosure of personal information is proscribed at the federal level by the Freedom of Information Act and Privacy Act of 1974. At the state and local level however, rules vary. Birth date and address information are both available through motor vehicle departments and their electronic databases are likely to be the main source of AnyBirthday.com's records. ${ }^{26}$ The availability of birth date information is therefore very likely to be related to local institutional rules regarding motor vehicle departments. Geography thus will influence the presence of innovators in the age sample, and a further issue in selection may involve the geographic mobility of the innovator, among other factors. The influence of this selection, together with the implications of assignment status, can be assessed by comparing observable means in the population across subsamples.

Table A.3 considers average team size, which is a source of further differences. Patents with provided zip codes have smaller team sizes than the U.S. average; team sizes in the subset of these patents for which the age of one innovator is known are slightly larger, but still smaller than the U.S. average. Controlling for other patent observables, in particular the assignment status, reduces the mean differences and brings the age sample quite closely in line with the U.S. mean. (See the last two columns of the table.) Having examined a number of other observables in the data, such as citations received and average tree size, I find that relatively small differences tend to exist in the raw data, and that these can be either entirely or largely explained by controlling for assignment status and team size. Most importantly, the age results in the text are all robust to the inclusion of assignment status, team size, and any other available controls.

Finally, looking at team size, specialization, and time lag trends in the age subsample, the results are similar in sign and significance as those presented in Section 4. The rate of increase in specialization is larger, and the rate of increase in team size is smaller. The time lag shows no trend. Reexamining trends in the entire data set by assignment status, I find that the team size trend is weaker among the unassigned category, which likely explains the weaker trend in the age subset. Similarly, I find that the specialization trend is stronger among the unassigned category, which likely explains the stronger trend in the age subset.

I conclude therefore that while the age subset is not a random sample of the U.S. innovator population, the differences tend to be explainable with other observables and, on the basis of including such observables in the analysis, the age results appear robust.

\footnotetext{
${ }^{25}$ Repeated requests to AnyBirthday.com to define their sources more explicitly have yet to produce a response.

${ }^{26}$ A federal law, the Driver's Privacy Protection Act of 1994, was introduced to give individuals increased privacy. The law requires motor vehicle departments to receive explicit prior consent from an individual before disclosing their personal information. However, the law makes an exception for cases where motor vehicles departments provide information to survey and marketing organizations. In that case, individual's consent is assumed unless the individual has opted-out on their own initiative. See Gellman (1995) for an in-depth discussion of the laws and legal history surrounding public records.
} 


\section{References}

[1] Aghion, Philippe and Howitt, Peter. "A Model of Growth through Creative Destruction," Econometrica, March 1992, 60, 323-351.

[2] —. Endogenous Growth Theory, Cambridge, MA: MIT Press, 1998.

[3] Baily, Martin N. and Chakrabarti, Alok K. "Innovation and Productivity in U.S. Industry," Brookings Papers on Economic Activity, 1985, 609-632.

[4] Ben-Porath, Yoram. "The Production of Human Capital and the Life Cycle of Earnings," Journal of Political Economy, August 1967, 75, 352-365.

[5] Cronin, Blaise, Shaw, Debora, and La Barre, Kathryn. "A Cast of Thousands: Coauthorship and Subauthorship Collaboration in the 20th Century as Manifested in the Scholarly Journal Literature of Psychology and Philosophy," Journal of the American Society for Information Science and Technology, 2003, 54(9), 855-871.

[6] —. "Visible, Less Visible, and Invisible Work: Patterns of Collaboration in 20th Century Chemistry," Journal of the American Society for Information Science and Technology, 2004, 55(2), 160-168.

[7] Evenson, Robert E. "International Invention: Implications for Technology Market Analysis," in Zvi Griliches, ed., RESD, Patents, and Productivity, Chicago, IL: University of Chicago Press, 1984, 89-123.

[8] — . "Patent Data by Industry: Evidence for Invention Potential Exhaustion?" Technology and Productivity: The Challenge for Economic Policy, 1991, Paris: OECD, 233-248.

[9] Gellman, Robert. "Public Records: Access, Privacy, and Public Policy," Center for Democracy and Technology Discussion Paper, April 1995, http://www.cdt.org/privacy/pubrecs/pubrec.html.

[10] Grossman, Gene M. and Helpman, Elhanan. Innovation and Growth in the Global Economy, Cambridge, MA: MIT Press, 1991.

[11] Grossman, Jerry. "The Evolution of the Mathematical Research Collaboration Graph," Congressus Numerantium, 2002, 158, 202-212.

[12] Hall, Bronwyn H., Jaffe, Adam B., and Trajtenberg, Manuel. "The NBER Patent Citations Data File: Lessons, Insights and Methodological Tools," NBER Working Paper No. 8498, October 2001.

[13] Hart, Oliver and Moore, John. "A Theory of Debt Based on the Inalienability of Human Capital," Quarterly Journal of Economics, November 1994, 109, 841-879.

[14] Henderson, Rebecca and Cockburn, Iain. "Scale, Scope, and Spillovers: The Determinants of Research Productivity in Drug Discovery," Rand Journal of Economics, Spring 1996, 27, 32-59.

[15] Hudson, John. "Trends in Multi-Authored Papers in Economics," Journal of Economic Perspectives, Summer 1996, 10, 153-158.

[16] Jones, Benjamin F. "Age and Great Invention," NBER Working Paper \#(TBD), 2005.

[17] Jones, Charles I. "R\&D-Based Models of Economic Growth," Journal of Political Economy, August 1995, 103, 759-784. 
[18] — . "Time Series Tests of Endogenous Growth Models," Quarterly Journal of Economics, May 1995, 110, 495-525.

[19] Kremer, Michael. "Population Growth and Technological Change: One Million B.C. to 1990," Quarterly Journal of Economics, August 1993, 108, 681-716.

[20] Kortum, Samuel S. "Equilibrium R\&D and the Decline in the Patent-R\&D Ratio: U.S. Evidence," American Economic Review Papers and Proceedings, May 1993, 83, 450-457.

[21] —. "Research, Patenting, and Technological Change," Econometrica, November 1997, 65, 1389-1419.

[22] Kuhn, Thomas. The Structure of Scientific Revolutions, Chicago, IL: University of Chicago Press, 1962.

[23] Laband, David and Tollison, Robert. "Intellectual Collaboration," Journal of Political Economy, June 2000, 108, 632-662.

[24] Machlup, Fritz. The Production and Distribution of Knowledge in the United States, Princeton, NJ: Princeton University Press, 1962, 170-176.

[25] Malone, Michael S. The Microprocessor: A Biography, New York, NY: Springer-Verlag New York, 1995.

[26] Mansfield, Edwin. "Patents and Innovation: An Empirical Study," Management Science, February 1986, 32, 173-181.

[27] McDowell, John, and Melvin, Michael. "The Determinants of Coauthorship: An Analysis of the Economics Literature," Review of Economics and Statistics, February 1983, 65, 155-160.

[28] Mokyr, Joel. The Lever of Riches, New York, NY: Oxford University Press, 1990.

[29] National Research Council, On Time to the Doctorate: A Study of the Lengthening Time to Completion for Doctorates in Science and Engineering, Washington, DC: National Academy Press, 1990.

[30] Romer, Paul M. "Endogenous Technological Change," Journal of Political Economy, October 1990, 98, S71-S102.

[31] Scotchmer, Suzanne. "Standing on the Shoulders of Giants - Cumulative Research and Patent Law", Journal of Economic Perspectives, Winter 1991, 5, 29-41.

[32] Segerstrom, Paul. "Endogenous Growth Without Scale Effects," American Economic Review, December 1998, 88, 1290-1310.

[33] Tilghman, Shirley (chair) et al. Trends in the Early Careers of Life Sciences, Washington, DC: National Academy Press, 1998.

[34] Weitzman, Martin L. "Recombinant Growth," Quarterly Journal of Economics, May 1998, 113, 331-360.

[35] Young, Alwyn. "Growth Without Scale Effects," Journal of Political Economy, February 1998, 106, 41-63.

[36] Zuckerman, Harriet and Merton, Robert. "Age, Aging, and Age Structure in Science," in Merton, Robert, The Sociology of Science, Chicago, IL: University of Chicago Press, 1973, 497-559. 
Table 1: Age Trends among Great Innovators

Dependent Variable: Age at Great Achievement

\begin{tabular}{ccc}
\hline & Nobel Prize Winners & Great Inventors \\
\hline $\begin{array}{c}\text { Year of Great } \\
\text { Achievement } \\
\text { (in 100's) }\end{array}$ & $5.83^{* * *}$ & $4.86^{* *}$ \\
Number of & $(1.37)$ & $(2.31)$ \\
observations & 544 & 286 \\
Time span & $1873-1998$ & $1900-91$ \\
Average age & 38.6 & 39.0 \\
$\mathrm{R}^{2}$ & 0.032 & 0.016 \\
\hline
\end{tabular}

NOTES:

(i) This table borrows from Jones (2005). Age trends are measured in years per century. Standard errors are given in parentheses.

(ii) Nobel Prize winners include all winners in Physics, Chemistry, Medicine, and Economics. Great inventors are taken from technological almanacs listing the great inventions of the $20^{\text {th }}$ century.

${ }^{* *}$ Indicates $95 \%$ confidence level. ${ }^{* * *}$ Indicates $99 \%$ confidence level. 
Table 2: Trends in Inventors per Patent

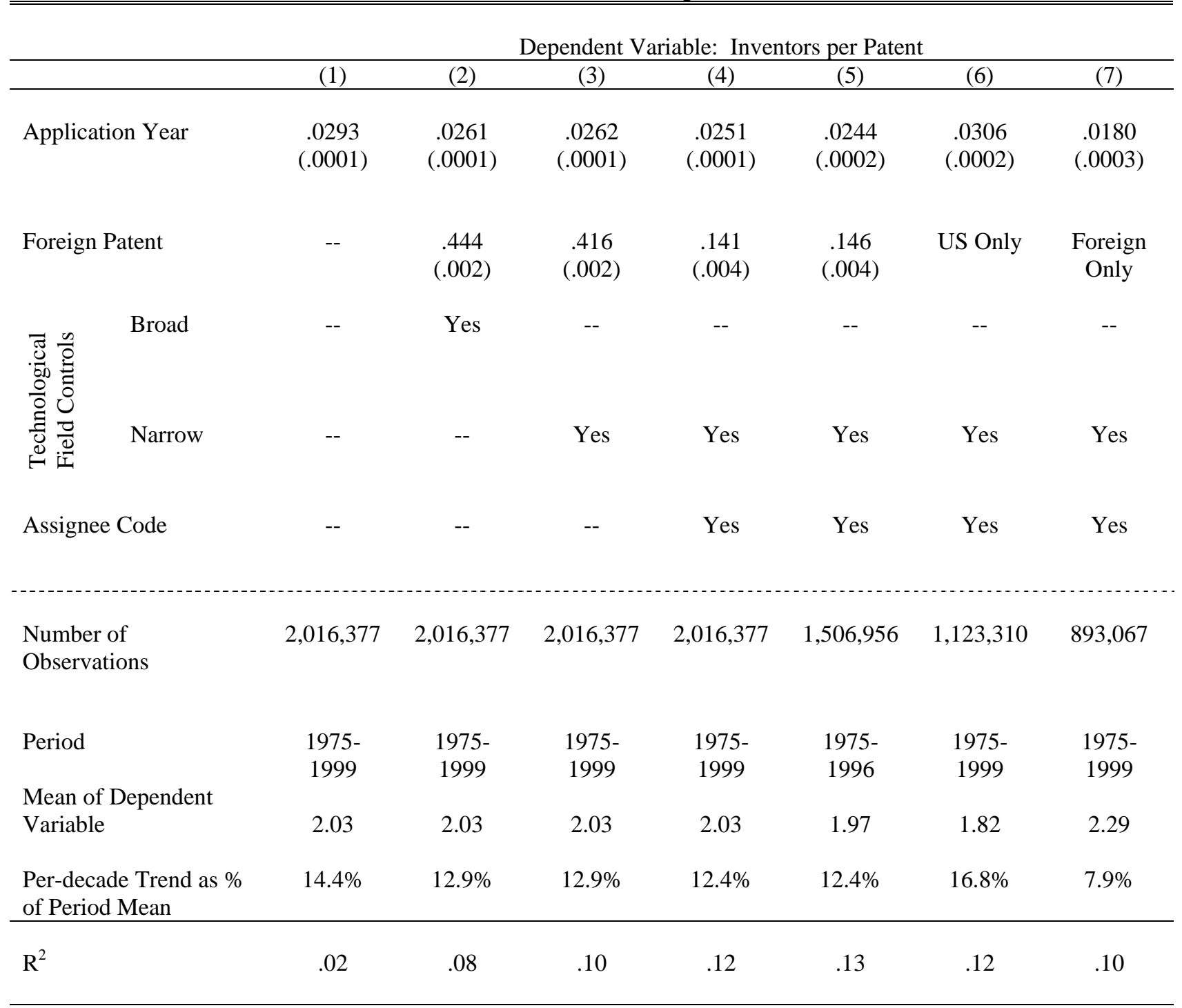

NOTES

(i) Regressions are OLS with standard errors in parentheses. Specifications (1) through (4) consider the entire universe of patents applied for between 1975 and 1999. Specification (5) considers only patents that were granted within three years after application (see discussion in text). Specifications (6) and (7) present separate trends for domestic and foreign source patents.

(ii) Foreign Patent is a dummy variable to indicate whether the first inventor listed with the patent has an address outside the U.S..

(iii) "Broad" technological controls include dummies for each of the 6 categories in Hall et al.’s most aggregated technological classification. "Narrow" technological controls include dummies for each category of their 36-category classification.

(iv) Upward trends persist when run separately for each technological field. Using the broad classification (six categories), the trends range from a low of .018 for "Other" to a high of .037 for "Chemical". Using the narrower classification scheme (thirty-six categories), the trends range from a low of .007 for "Apparel \&Textile" to .051 for "Organic Compounds". The smallest t-statistic for any of these trends is 7.76.

(v) Assignee code controls are seven dummy variables that define who holds the rights to the patent. Most patent rights are held by US or foreign corporations (80\%), while a minority remain unassigned $(17 \%)$ at the time the patent is issued. Table A.2 describes the assignee codes in further detail. Running the time trends separately for the individual assignee codes shows that the team size trends range from a low of .005 for the unassigned category to a high of .039 for US non-government institutions. The lowest t-statistic for any of these trends is 5.38. 
Table 3: Trends in Age at First Innovation

\begin{tabular}{|c|c|c|c|c|c|c|c|}
\hline & \multicolumn{7}{|c|}{ Dependent Variable: Age at Application } \\
\hline & $(1)$ & $(2)$ & $(3)$ & $(4)$ & $(5)$ & $(6)$ & $(7)$ \\
\hline Application Year & $\begin{array}{l}.0657 \\
(.0095)\end{array}$ & $\begin{array}{l}.0666 \\
(.0095)\end{array}$ & $\begin{array}{l}.0671 \\
(.0095)\end{array}$ & $\begin{array}{l}.0671 \\
(.0099)\end{array}$ & $\begin{array}{l}.0687 \\
(.0097)\end{array}$ & $\begin{array}{l}.0530 \\
(.0107)\end{array}$ & $\begin{array}{l}.0584 \\
(.0109)\end{array}$ \\
\hline Broad & -- & Yes & -- & -- & -- & -- & -- \\
\hline 总鸹 Narrow & -- & -- & Yes & Yes & Yes & -- & Yes \\
\hline Assignee Code & -- & -- & -- & Yes & Yes & -- & Yes \\
\hline Team Size & -- & -- & -- & -- & $\begin{array}{l}-.0630 \\
(.0273)\end{array}$ & -- & $\begin{array}{l}-.0348 \\
(.0306)\end{array}$ \\
\hline Number of observations & 6,541 & 6,541 & 6,541 & 6,541 & 6,541 & 5,102 & 5,102 \\
\hline Period & $\begin{array}{l}1985- \\
1999\end{array}$ & $\begin{array}{l}1985- \\
1999\end{array}$ & $\begin{array}{l}1985- \\
1999\end{array}$ & $\begin{array}{l}1985- \\
1999\end{array}$ & $\begin{array}{l}1985- \\
1999\end{array}$ & $\begin{array}{l}1985- \\
1999\end{array}$ & $\begin{array}{l}1985- \\
1999\end{array}$ \\
\hline Age Range & $25-35$ & $25-35$ & $25-35$ & $25-35$ & 25-35 & $23-33$ & $23-33$ \\
\hline \multicolumn{7}{|l|}{ Mean of Dependent } & 29.3 \\
\hline $\begin{array}{l}\text { Per-decade Trend as \% } \\
\text { of Period Mean }\end{array}$ & $2.1 \%$ & $2.1 \%$ & $2.2 \%$ & $2.2 \%$ & $2.2 \%$ & $1.8 \%$ & $2.0 \%$ \\
\hline $\mathrm{R}^{2}$ & .007 & .010 & .020 & .020 & .021 & .005 & .018 \\
\hline \multicolumn{8}{|c|}{$\begin{array}{l}\text { NOTES } \\
\text { (i) Regressions are OLS, with standard errors in parentheses. All regressions look only at those innovators for whom } \\
\text { we have age data and who appear for the first time in the data set in or after } 1985 \text {. Specifications (1) through (5) } \\
\text { consider those innovators who appear for the first time between ages } 25 \text { and } 35 \text {. Specifications (6) and (7) consider } \\
\text { those innovators who appear for the first time between ages } 23 \text { and } 33 \text {. } \\
\text { (ii) "Broad" technological controls include dummies for each of the } 6 \text { categories in Hall et al.'s most aggregated } \\
\text { technological classification. "Narrow" technological controls include dummies for each classification in their 36- } \\
\text { category measure. The upward age trend persists when run separately in each of Hall et al's broad technology classes. } \\
\text { These trends are significant in } 5 \text { of the } 6 \text { categories, with similar trend coefficients as when the data are pooled. } \\
\text { Upward trends are also found in } 29 \text { of } 36 \text { categories when using Hall et al.'s narrow technology classification. Here } \\
12 \text { categories show significant upward trends. Sample sizes drop considerably when the data is divided into these } 36 \\
\text { categories. The one case of a significant downward trend (category \#23, Computer Peripherals) has } 42 \text { observations. } \\
\text { (iii) Assignee code controls are seven dummy variables that define who holds the rights to the patent. Table A.2 } \\
\text { describes the assignee codes in further detail. The upward age trends persist when run separately for each assignee } \\
\text { code and are similar in magnitude to the trends in the table above. }\end{array}$} \\
\hline
\end{tabular}


Table 4: Trends in Probability of Field Jump

Dependent Variable: Probability of Switching Technological Field

\begin{tabular}{|c|c|c|c|c|c|c|c|c|}
\hline & $\begin{array}{l}(1) \\
414\end{array}$ & $\begin{array}{l}(2) \\
414\end{array}$ & $\begin{array}{l}\text { (3) } \\
36\end{array}$ & $\begin{array}{l}\text { (4) } \\
36\end{array}$ & $\begin{array}{c}(5) \\
6\end{array}$ & $\begin{array}{c}\text { (6) } \\
6\end{array}$ & $\begin{array}{l}(7) \\
414\end{array}$ & $\begin{array}{l}(8) \\
414\end{array}$ \\
\hline Application Year & $\begin{array}{l}-3.4 \mathrm{e}-3 \\
(.19 \mathrm{e}-3)\end{array}$ & $\begin{array}{l}-3.2 \mathrm{e}-3 \\
(.19 \mathrm{e}-3)\end{array}$ & $\begin{array}{l}-2.5 e-3 \\
(.19 e-3)\end{array}$ & $\begin{array}{c}-2.8 \mathrm{e}-3 \\
(.19 \mathrm{e}-3)\end{array}$ & $\begin{array}{l}-1.9 e-3 \\
(.17 e-3)\end{array}$ & $\begin{array}{l}-2.3 e-3 \\
(.17 e-3)\end{array}$ & $\begin{array}{l}-5.1 \mathrm{e}-3 \\
(.12 \mathrm{e}-3)\end{array}$ & $\begin{array}{l}-3.0 \mathrm{e}-3 \\
(.11 \mathrm{e}-3)\end{array}$ \\
\hline Foreign Patent & -- & $\begin{array}{c}.0076 \\
(.0039)\end{array}$ & -- & $\begin{array}{l}-.0041 \\
(.0038)\end{array}$ & -- & $\begin{array}{c}.0002 \\
(.0035)\end{array}$ & -- & $\begin{array}{l}-.0005 \\
(.0029)\end{array}$ \\
\hline $\begin{array}{l}\text { Time Between } \\
\text { Applications }\end{array}$ & -- & $\begin{array}{c}.0225 \\
(.0012)\end{array}$ & -- & $\begin{array}{c}.0206 \\
(.0012)\end{array}$ & -- & $\begin{array}{c}.0154 \\
(.0011)\end{array}$ & -- & $\begin{array}{l}.0228 \\
(.0004)\end{array}$ \\
\hline $\begin{array}{l}\text { Technological } \\
\text { Field Controls } \\
\text { (first patent) }\end{array}$ & -- & Yes & -- & Yes & -- & Yes & -- & Yes \\
\hline $\begin{array}{l}\text { Assignee Code } \\
\text { (first patent) }\end{array}$ & -- & Yes & -- & Yes & -- & Yes & -- & Yes \\
\hline $\begin{array}{l}\text { Number of } \\
\text { observations }\end{array}$ & 215,855 & 215,855 & 215,855 & 215,855 & 215,855 & 215,855 & 359,405 & 359,405 \\
\hline Period & $\begin{array}{l}1975- \\
1993\end{array}$ & $\begin{array}{l}1975- \\
1993\end{array}$ & $\begin{array}{l}1975- \\
1993\end{array}$ & $\begin{array}{l}1975- \\
1993\end{array}$ & $\begin{array}{l}1975- \\
1993\end{array}$ & $\begin{array}{l}1975- \\
1993\end{array}$ & $\begin{array}{c}1975- \\
1999\end{array}$ & $\begin{array}{l}1975- \\
1999\end{array}$ \\
\hline $\begin{array}{l}\text { Mean of } \\
\text { Dependent } \\
\text { Variable }\end{array}$ & .535 & .535 & .423. & .423. & .294 & 294 & .556 & .556 \\
\hline $\begin{array}{l}\text { Per-decade } \\
\text { Trend as \% of } \\
\text { Period Mean }\end{array}$ & $-6.4 \%$ & $-6.0 \%$ & $-5.9 \%$ & $-6.4 \%$ & $-6.5 \%$ & $-7.8 \%$ & $-9.4 \%$ & $-5.6 \%$ \\
\hline (Pseudo) $\mathrm{R}^{2}$ & .0011 & .018 & .0006 & .019 & .0005 & .017 & .004 & .026 \\
\hline
\end{tabular}

NOTES

(i) Results are for probit estimation, with coefficients reported at mean values and standard errors in parentheses. The coefficient for the Foreign dummy is reported over the $0-1$ range.

(ii) The dependent variable is 0 if an inventor does not switch fields between two consecutive innovations. The dependent variable is 1 if the inventor does switch fields. Column headings define the field classification used to determine the dependent variable: "414" indicates the 414-category technological class definition of the USPTO; "36" and "6" refer to the aggregated measures defined by Hall et al (2001).

(iii) Specifications (1) through (6) consider "fast" innovators -- only those consecutive patents with no more than 3 years between applications and with no more than 3 years delay between application and grant. (See discussion in text.) Specifications (7) and (8) consider all consecutive patents.

(iv) Technological field controls are dummies for the 36 categories defined by Hall et al (2001). The reported regressions use the technological field of the initial patent. Using the field of the second patent has no effect on the results. Running the regressions separately by technology category shows that the trends persist in 6 of 6 categories using Hall et al.'s broad technology classification and 34 of 36 categories using Hall et al's narrow classification with significant trends in 20.

(v) Assignee code controls are seven dummy variables that define who holds the rights to the patent. Table A.2 describes the assignee codes in further detail. The declining probability of field jump persists when the trend is examined within each assignment code, although the significance of the trend disappears in the rarer classifications. 
Table 5: Trends in Time Lag

Dependent Variable: Time Lag Between Consecutive Patent Applications

\begin{tabular}{|c|c|c|c|c|c|c|}
\hline & (1) & $(2)$ & (3) & (4) & (5) & (6) \\
\hline Application Year & $\begin{array}{l}0.30 \mathrm{e}-3 \\
(.14 \mathrm{e}-3)\end{array}$ & $\begin{array}{c}1.2 \mathrm{e}-3 \\
(.14 \mathrm{e}-3)\end{array}$ & $\begin{array}{l}0.54 \mathrm{e}-3 \\
(.14 \mathrm{e}-3)\end{array}$ & $\begin{array}{c}2.2 \mathrm{e}-3 \\
(.35 \mathrm{e}-3)\end{array}$ & $\begin{array}{c}2.8 e-3 \\
(.35 e-3)\end{array}$ & $\begin{array}{c}2.0 \mathrm{e}-3 \\
(.35 \mathrm{e}-3)\end{array}$ \\
\hline Foreign Patent & -- & $\begin{array}{l}-.0736 \\
(.0016)\end{array}$ & $\begin{array}{l}-.0591 \\
(.0016)\end{array}$ & -- & $\begin{array}{l}-.0526 \\
(.0042)\end{array}$ & $\begin{array}{l}-.0522 \\
(.0042)\end{array}$ \\
\hline $\begin{array}{l}\text { Team Size } \\
\text { (second patent) }\end{array}$ & -- & $\begin{array}{l}-.0156 \\
(.0004)\end{array}$ & $\begin{array}{l}-.0099 \\
(.0004)\end{array}$ & -- & -- & -- \\
\hline $\begin{array}{l}\text { Same Team Size } \\
\text { Dummy }\end{array}$ & -- & $\begin{array}{l}-.0474 \\
(.0016)\end{array}$ & $\begin{array}{l}-.0515 \\
(.0016)\end{array}$ & -- & -- & -- \\
\hline Field Jump Dummy & -- & $\begin{array}{l}.115 \\
(.002)\end{array}$ & $\begin{array}{l}.115 \\
(.002)\end{array}$ & -- & $\begin{array}{l}.081 \\
(.004)\end{array}$ & $\begin{array}{l}.083 \\
(.004)\end{array}$ \\
\hline $\begin{array}{l}\text { Technological Field } \\
\text { Controls } \\
\text { (second patent) }\end{array}$ & -- & -- & Yes & -- & -- & Yes \\
\hline $\begin{array}{l}\text { Number of } \\
\text { observations }\end{array}$ & $1,430,144$ & $1,430,144$ & $1,430,144$ & 215,855 & 215,855 & 215,855 \\
\hline Period & 1975-1993 & 1975-1993 & 1975-1993 & 1975-1993 & 1975-1993 & 1975-1993 \\
\hline $\begin{array}{l}\text { Mean of Dependent } \\
\text { Variable } \\
\text { (see note (iv)) }\end{array}$ & .749 & .749 & .749 & .793 & .793 & .793 \\
\hline $\begin{array}{l}\text { Per-decade Trend as } \\
\% \text { of Period Mean } \\
\text { (see note (iv)) }\end{array}$ & $0.4 \%$ & $1.6 \%$ & $0.7 \%$ & $2.8 \%$ & $3.5 \%$ & $2.5 \%$ \\
\hline $\mathrm{R}^{2}$ & .0000 & .0077 & .0157 & .0002 & .0028 & .0136 \\
\hline
\end{tabular}

\section{NOTES}

(i) Regressions are OLS, with standard errors in parentheses.

(ii) All specifications consider "fast" innovators -- only those consecutive patents with no more than 3 years between applications and with no more than 3 years delay between application and grant. (See discussion in text.) (iii) Specifications (1) to (3) consider all consecutive patents in this time period. Specifications (4) through (6) consider time lags by solo inventors.

(iv) The dependent variable is an integer varying between 0 and 3 . Period means are underestimated due to the integer nature of the application year, because two applications in the same calendar year are calculated to have a time lag of zero. This biases down the mean and biases up the percentage trend.

(v) Technological field controls are dummies for the 36 categories defined by Hall et al (2001). 
Table 6: Mean differences across Technological Categories

\begin{tabular}{|c|c|c|c|c|c|c|c|c|}
\hline \multicolumn{2}{|r|}{$\begin{array}{l}\text { Technological Classification } \\
\text { (Hall et al. 2001) }\end{array}$} & \multirow[b]{2}{*}{ Code } & \multicolumn{2}{|c|}{$\begin{array}{l}\text { Age at First } \\
\text { Innovation }\end{array}$} & \multicolumn{2}{|c|}{$\begin{array}{l}\text { Inventors per } \\
\text { Patent }\end{array}$} & \multicolumn{2}{|c|}{$\begin{array}{l}\text { Probability of } \\
\text { Field Jump }\end{array}$} \\
\hline 6 & 36 & & Obs & Mean & Obs & Mean & Obs & Mean \\
\hline \multirow{7}{*}{ 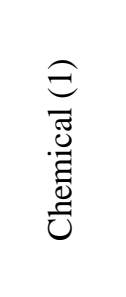 } & Agriculture, Food, Textiles & 11 & 12 & 31.1 & 16,100 & 2.41 & 2,500 & 0.48 \\
\hline & Coating & 12 & 53 & 29.2 & 29,800 & 2.23 & 4,300 & 0.64 \\
\hline & Gas & 13 & 17 & 30.3 & 9,200 & 1.96 & 1,700 & 0.59 \\
\hline & Organic Compounds & 14 & 51 & 29.5 & 59,600 & 2.56 & 7,000 & 0.34 \\
\hline & Resins & 15 & 44 & 29.3 & 67,200 & 2.51 & 7,500 & 0.36 \\
\hline & Miscellaneous_Chemical & 19 & 331 & 29.3 & 197,100 & 2.23 & 29,500 & 0.43 \\
\hline & Entire category & & 508 & 29.4 & 379,200 & 2.33 & 52,100 & 0.43 \\
\hline \multirow{5}{*}{ 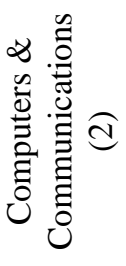 } & Communications & 21 & 264 & 29.3 & 92,700 & 1.99 & 15,000 & 0.41 \\
\hline & Computer Hardware \& Software & 22 & 162 & 29.8 & 80,400 & 2.26 & 10,200 & 0.44 \\
\hline & Computer Peripherals & 23 & 37 & 29.3 & 22,100 & 2.37 & 2,800 & 0.51 \\
\hline & Information Storage & 24 & 43 & 28.9 & 41,300 & 2.21 & 6,700 & 0.39 \\
\hline & Entire category & & 506 & 29.4 & 236,700 & 2.16 & 34,500 & 0.42 \\
\hline \multirow{5}{*}{ 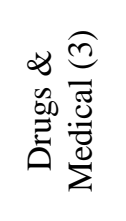 } & Drugs & 31 & 74 & 29.9 & 65,200 & 2.90 & 6,300 & 0.25 \\
\hline & Surgery \& Medical Instruments & 32 & 268 & 29.8 & 59,900 & 1.86 & 12,400 & 0.29 \\
\hline & Biotechnology & 33 & 46 & 30.5 & 22,700 & 2.75 & 1,800 & 0.38 \\
\hline & Misc_-Drugs \& Medical & 39 & 68 & 29.1 & 13,600 & 1.66 & 3,500 & 0.35 \\
\hline & Entire category & & 456 & 29.8 & 161,500 & 2.39 & 23,800 & 0.29 \\
\hline \multirow{8}{*}{ 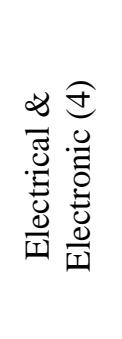 } & Electrical Devices & 41 & 111 & 29.3 & 61,000 & 1.77 & 12,700 & 0.48 \\
\hline & Electrical Lighting & 42 & 90 & 29.6 & 31,300 & 1.96 & 5,700 & 0.43 \\
\hline & Measuring \& Testing & 43 & 116 & 29.2 & 57,700 & 1.94 & 10,000 & 0.51 \\
\hline & Nuclear \& X-rays & 44 & 52 & 29.7 & 30,200 & 2.08 & 4,700 & 0.50 \\
\hline & Power Systems & 45 & 128 & 29.4 & 68,900 & 1.94 & 13,000 & 0.51 \\
\hline & Semiconductor Devices & 46 & 49 & 29.3 & 44,700 & 2.25 & 7,100 & 0.34 \\
\hline & Misc_Electrical & 49 & 104 & 29.1 & 49,100 & 1.97 & 8,900 & 0.51 \\
\hline & Entire category & & 650 & 29.3 & 343,300 & 1.97 & 61,700 & 0.48 \\
\hline \multirow{7}{*}{ 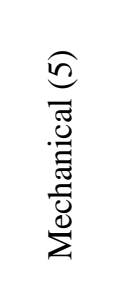 } & Materials Processing \& Handling & 51 & 241 & 29.4 & 100,000 & 1.79 & 21,700 & 0.48 \\
\hline & Metal Working & 52 & 87 & 28.8 & 58,100 & 2.11 & 10,400 & 0.54 \\
\hline & Motors, Engines \& Parts & 53 & 83 & 29.4 & 73,300 & 1.85 & 16,200 & 0.41 \\
\hline & Optics & 54 & 57 & 29.0 & 48,000 & 2.15 & 8,100 & 0.37 \\
\hline & Transportation & 55 & 273 & 29.0 & 56,800 & 1.66 & 12,000 & 0.45 \\
\hline & Misc-Mechanical & 59 & 449 & 29.1 & 96,800 & 1.64 & 22,400 & 0.49 \\
\hline & Entire category & & 1,190 & 29.1 & 433,300 & 1.83 & 90,500 & 0.46 \\
\hline \multirow{10}{*}{ 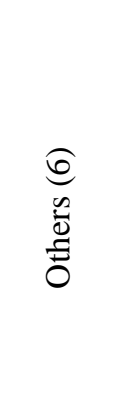 } & Agriculture, Husbandry, Food & 61 & 250 & 29.1 & 41,200 & 1.75 & 7,600 & 0.41 \\
\hline & Amusement Devices & 62 & 269 & 29.4 & 20,900 & 1.41 & 4,300 & 0.37 \\
\hline & Apparel \& Textile & 63 & 211 & 29.1 & 32,400 & 1.57 & 7,600 & 0.37 \\
\hline & Earth Working \& Wells & 64 & 100 & 29.6 & 27,800 & 1.69 & 6,600 & 0.36 \\
\hline & Furniture, House Fixtures & 65 & 346 & 29.1 & 41,000 & 1.42 & 9,400 & 0.50 \\
\hline & Heating & 66 & 58 & 30.0 & 26,300 & 1.75 & 6,100 & 0.48 \\
\hline & Pipes \& Joints & 67 & 45 & 29.2 & 17,100 & 1.58 & 4,500 & 0.61 \\
\hline & Receptacles & 68 & 298 & 29.4 & 40,700 & 1.51 & 10,100 & 0.47 \\
\hline & Misc-Others & 69 & 846 & 29.2 & 167,800 & 1.73 & 35,200 & 0.48 \\
\hline & Entire category & & 2,423 & 29.3 & 415,600 & 1.64 & 91,000 & 0.46 \\
\hline
\end{tabular}

NOTES

(i) Age at first innovation includes observations of those innovators who appear after 1985 in the data set and between the ages of 23 and 33. Results are similar, with higher mean and even less variance, for 25-35 year olds. (ii) Probability of field jump is probability of switching categories for solo innovators using 36-category measure. 
Table 7: Inventors per Patent vs. Tree Size

\begin{tabular}{|c|c|c|c|c|c|c|c|}
\hline & \multicolumn{7}{|c|}{ Dependent Variable: Inventors per Patent } \\
\hline & (1) & (2) & (3) & (4) & (5) & (6) & (7) \\
\hline $\begin{array}{l}\text { Normalized Variation in } \\
\text { Tree Size }\end{array}$ & $\begin{array}{l}.0849 \\
(.0010)\end{array}$ & $\begin{array}{l}.0961 \\
(.0010)\end{array}$ & $\begin{array}{l}.0995 \\
(.0011)\end{array}$ & $\begin{array}{l}.120 \\
(.001)\end{array}$ & $\begin{array}{l}.133 \\
(.001)\end{array}$ & $\begin{array}{l}.107 \\
(.001)\end{array}$ & $\begin{array}{l}.152 \\
(.001)\end{array}$ \\
\hline $\begin{array}{l}\text { Normalized Variation in } \\
\text { Tree Size, Squared }\end{array}$ & $\begin{array}{l}.0609 \\
(.0007)\end{array}$ & $\begin{array}{l}.0545 \\
(.0007)\end{array}$ & $\begin{array}{l}.0545 \\
(.0007)\end{array}$ & $\begin{array}{l}.0341 \\
(.0007)\end{array}$ & $\begin{array}{l}.0257 \\
(.0009)\end{array}$ & $\begin{array}{l}.0356 \\
(.0011)\end{array}$ & $\begin{array}{l}.0404 \\
(.0009)\end{array}$ \\
\hline Foreign Patent & -- & $\begin{array}{c}.446 \\
(.002)\end{array}$ & $\begin{array}{c}.442 \\
(.002)\end{array}$ & $\begin{array}{l}.420 \\
(.002)\end{array}$ & US Only & $\begin{array}{l}\text { Foreign } \\
\text { Only }\end{array}$ & $\begin{array}{l}.371 \\
(.003)\end{array}$ \\
\hline $\begin{array}{l}\text { Normalized Variation in } \\
\text { Direct Citations Made }\end{array}$ & -- & -- & $\begin{array}{l}-.0094 \\
(.0011)\end{array}$ & -- & -- & -- & -- \\
\hline $\begin{array}{l}\text { Technological Field } \\
\text { Controls }\end{array}$ & -- & -- & -- & Yes & Yes & Yes & Yes \\
\hline $\begin{array}{l}\text { Application Year } \\
\text { Dummies }\end{array}$ & Yes & Yes & Yes & Yes & Yes & Yes & Yes \\
\hline Number of observations & $1,969,908$ & 1,969,908 & $1,969,908$ & $1,969,908$ & $1,103,402$ & 866,506 & $1,330,210$ \\
\hline Period & $\begin{array}{l}1975- \\
1999\end{array}$ & $\begin{array}{l}1975- \\
1999\end{array}$ & $\begin{array}{l}1975- \\
1999\end{array}$ & $\begin{array}{l}1975- \\
1999\end{array}$ & $\begin{array}{l}1975- \\
1999\end{array}$ & $\begin{array}{l}1975- \\
1999\end{array}$ & $\begin{array}{l}1985- \\
1999\end{array}$ \\
\hline $\begin{array}{l}\text { Mean of Dependent } \\
\text { Variable }\end{array}$ & 2.02 & 2.02 & 2.02 & 2.02 & 1.82 & 2.27 & 2.13 \\
\hline $\mathrm{R}^{2}$ & .026 & .050 & .050 & .100 & .090 & .083 & .079 \\
\hline
\end{tabular}

NOTES

(i) Regressions are OLS with standard errors in parentheses. Specifications (1) through (4) consider the entire universe of patents applied for between 1975 and 1999. Specification (5) and (6) consider separately patents from domestic vs. foreign sources. Specification (7) considers cross-sections from the later part of the time period.

(ii) Normalized Variation in Tree Size is the deviation from the year mean tree size, divided by the year standard deviation in tree size. "Tree size" is the log of the number of nodes in the citations tree behind any patent.

(iii) Normalized Variation in Direct Citations Made captures variation in the number of citations to prior art listed on a patent application. It is the deviation from the year mean number of citations, divided by the year standard deviation in the number of citations.

(iv) Technological field controls include dummies for each of Hall et al.'s 36-category measure.

(v) The number of observations here is slightly smaller than for the time trend analysis in Table 1 because a few patents do not cite other US patents, hence no citation tree can be built; these patents are dropped from the analysis. 
Table 8: Age vs. Tree Size

\begin{tabular}{|c|c|c|c|c|c|c|c|c|}
\hline & \multicolumn{8}{|c|}{ Dependent Variable: Age at application for first patent } \\
\hline & $(1)$ & $(2)$ & $(3)$ & $(4)$ & (5) & $(6)$ & $(7)$ & $(8)$ \\
\hline $\begin{array}{l}\text { Normalized Variation } \\
\text { in Tree Size }\end{array}$ & $\begin{array}{l}-.007 \\
(.032)\end{array}$ & $\begin{array}{l}-.005 \\
(.036)\end{array}$ & $\begin{array}{l}.114 \\
(.035)\end{array}$ & $\begin{array}{l}.084 \\
(.040)\end{array}$ & $\begin{array}{l}.059 \\
(.043)\end{array}$ & $\begin{array}{l}.097 \\
(.030)\end{array}$ & $\begin{array}{l}.113 \\
(.046)\end{array}$ & $\begin{array}{l}.030 \\
(.026)\end{array}$ \\
\hline Team Size & -- & $\begin{array}{l}-.054 \\
(.027)\end{array}$ & -- & $\begin{array}{l}-.036 \\
(.030)\end{array}$ & $\begin{array}{l}-.038 \\
(.030)\end{array}$ & $\begin{array}{l}-.024 \\
(.025)\end{array}$ & $\begin{array}{l}.008 \\
(.035)\end{array}$ & $\begin{array}{l}-.029 \\
(.019)\end{array}$ \\
\hline $\begin{array}{l}\text { Normalized Variation } \\
\text { in Direct Citations }\end{array}$ & -- & -- & -- & -- & $\begin{array}{c}.064 \\
(.044)\end{array}$ & -- & -- & -- \\
\hline $\begin{array}{l}\text { Technological Field } \\
\text { Controls }\end{array}$ & -- & Yes & -- & Yes & Yes & Yes & Yes & Yes \\
\hline $\begin{array}{l}\text { Application Year } \\
\text { Dummies }\end{array}$ & Yes & Yes & Yes & Yes & Yes & Yes & Yes & Yes \\
\hline $\begin{array}{l}\text { Number of } \\
\text { observations }\end{array}$ & 6,486 & 6,486 & 5,058 & 5,058 & 5,058 & 8,434 & 3,630 & 3,588 \\
\hline Period & $\begin{array}{l}1985- \\
1999\end{array}$ & $\begin{array}{l}1985- \\
1999\end{array}$ & $\begin{array}{l}1985- \\
1999\end{array}$ & $\begin{array}{l}1985- \\
1999\end{array}$ & $\begin{array}{l}1985- \\
1999\end{array}$ & $\begin{array}{l}1975- \\
1999\end{array}$ & $\begin{array}{l}1985- \\
1999\end{array}$ & $\begin{array}{l}1985- \\
1999\end{array}$ \\
\hline Age Range & $25-35$ & $25-35$ & $23-33$ & $23-33$ & $23-33$ & $23-33$ & $21-31$ & 28-33 \\
\hline $\begin{array}{l}\text { Mean of Dependent } \\
\text { Variable }\end{array}$ & 31.0 & 31.0 & 29.34 & 29.3 & 29.2 & 29.2 & 27.7 & 30.7 \\
\hline $\mathrm{R}^{2}$ & .009 & .022 & .009 & .021 & .012 & .020 & .025 & .020 \\
\hline $\begin{array}{l}\text { NOTES } \\
\text { (i) Regressions are OLs } \\
\text { whom we have age dat } \\
\text { Specifications (3) throu } \\
\text { slightly younger innova } \\
\text { Specifications (6) cons } \\
\text { the post-1985 period, fo } \\
\text { (ii) Normalized Variati } \\
\text { standard deviation in tr } \\
\text { patent. } \\
\text { (iii) Normalized Variat } \\
\text { listed on a patent applic } \\
\text { standard deviation in th } \\
\text { (iv) The number of obs } \\
\text { few patents do not cite } \\
\text { analysis. } \\
\text { (v) Technological field }\end{array}$ & $\begin{array}{l}\text { with star } \\
\text { Specific } \\
\text { h (6) con } \\
\text { ors, and s } \\
\text { lers cross- } \\
\text { which w } \\
\text { n in Tree } \\
\text { e size. "T } \\
\text { on in Dire } \\
\text { tion. It is } \\
\text { number } \\
\text { rvations h } \\
\text { ther US P } \\
\text { ontrols ir }\end{array}$ & $\begin{array}{l}\text { ard error } \\
\text { ions (1) } \\
\text { der inno } \\
\text { ecificatic } \\
\text { ections p } \\
\text { can be c } \\
\text { ize is the } \\
\text { ee size” i } \\
\text { Citation } \\
\text { he devia } \\
\text { citations } \\
\text { re is sligl } \\
\text { ents, her } \\
\text { te dum }\end{array}$ & $\begin{array}{l}\text { 8) consi } \\
\text { ed over } \\
\text { ident tha } \\
\text { viation } f \\
\text { ee log of } \\
\text { lade cap } \\
\text { from th } \\
\text { smaller } \\
\text { no citati }\end{array}$ & $\begin{array}{l}\text { es. All rt } \\
\text { er first ir } \\
\text { 3-33 age } \\
\text { s the latt } \\
\text { entire ti } \\
\text { ve are wi } \\
\text { n the yea } \\
\text { e number } \\
\text { es variat } \\
\text { jear mea } \\
\text { an for the } \\
\text { tree can }\end{array}$ & $\begin{array}{l}\text { essions } \\
\text { vations } \\
\text { ndow. } \\
\text { half of } t \\
\text { period; } \\
\text { ssing an } \\
\text { nean tre } \\
\text { f nodes i } \\
\text { in the n } \\
\text { mumber o } \\
\text { me trenc } \\
\text { built; th }\end{array}$ & $\begin{array}{l}\text { k only a } \\
\text { the } 25-3 \\
\text { cificatio } \\
23-33 \text { as } \\
\text { e other s } \\
\text { novator' } \\
\text { ze, divic } \\
\text { he citati } \\
\text { hber of c } \\
\text { itations, } \\
\text { nalysis i } \\
\text { e patents }\end{array}$ & $\begin{array}{l}\text { ose inno } \\
\text { ge wind } \\
\text { 7) consic } \\
\text { vindow. } \\
\text { ification } \\
\text { rst paten } \\
\text { by the y } \\
\text { tree beh } \\
\text { ions to } p \\
\text { ided by } \\
\text { able } 2 \text { be } \\
\text { droppe }\end{array}$ & $\begin{array}{l}\text { tors for } \\
\text { any } \\
\text { ocus on } \\
\text { use a } \\
\text { rom the }\end{array}$ \\
\hline
\end{tabular}


Table 9: Field Jump vs. Tree Size

Dependent Variable: Probability of Switching Technological Field

\begin{tabular}{|c|c|c|c|c|c|c|}
\hline & (1) & (2) & (3) & (4) & (5) & (6) \\
\hline $\begin{array}{l}\text { Normalized Variation } \\
\text { in Tree Size }\end{array}$ & $\begin{array}{l}-.0072 \\
(.0008)\end{array}$ & $\begin{array}{l}-.0074 \\
(.0008)\end{array}$ & $\begin{array}{l}-.0059 \\
(.0008)\end{array}$ & $\begin{array}{l}-.0095 \\
(.0009)\end{array}$ & $\begin{array}{l}-.0144 \\
(.0012)\end{array}$ & $\begin{array}{l}-.0184 \\
(.0017)\end{array}$ \\
\hline Foreign Patent & -- & $\begin{array}{l}-.0125 \\
(.0018)\end{array}$ & $\begin{array}{l}-.0108 \\
(.0018)\end{array}$ & $\begin{array}{l}-.0129 \\
(.0018)\end{array}$ & $\begin{array}{l}-.0135 \\
(.0023)\end{array}$ & $\begin{array}{c}.0032 \\
(.0032)\end{array}$ \\
\hline $\begin{array}{l}\text { Time Between } \\
\text { Applications }\end{array}$ & -- & -- & $\begin{array}{c}.0226 \\
(.0004)\end{array}$ & $\begin{array}{c}.0232 \\
(.0004)\end{array}$ & $\begin{array}{c}.0215 \\
(.0012)\end{array}$ & $\begin{array}{c}.0143 \\
(.0017)\end{array}$ \\
\hline $\begin{array}{l}\text { Technological Field } \\
\text { Controls (first patent) }\end{array}$ & -- & -- & -- & Yes & Yes & Yes \\
\hline $\begin{array}{l}\text { Application Year } \\
\text { Dummies }\end{array}$ & Yes & Yes & Yes & Yes & Yes & Yes \\
\hline Number of observations & 353,762 & 353,762 & 353,762 & 353,762 & 212,274 & 110,511 \\
\hline Period & $\begin{array}{l}1975- \\
1999\end{array}$ & $\begin{array}{l}1975- \\
1999\end{array}$ & $\begin{array}{l}1975- \\
1999\end{array}$ & $\begin{array}{l}1975- \\
1999\end{array}$ & $\begin{array}{l}1975- \\
1993\end{array}$ & $\begin{array}{l}1985- \\
1993\end{array}$ \\
\hline $\begin{array}{l}\text { Mean of Dependent } \\
\text { Variable }\end{array}$ & .551 & .551 & .551 & .551 & .536 & .520 \\
\hline (Pseudo) $\mathrm{R}^{2}$ & .0039 & .0039 & .0117 & .0251 & .0171 & .0159 \\
\hline
\end{tabular}

NOTES

(i) Results are for probit estimation, with coefficients reported at mean values and standard errors in parentheses. The coefficient for the Foreign dummy is reported over the $0-1$ range. Only solo inventors are considered. Specifications (1) through (4) consider the entire set of solo inventors. Specification (5) considers only those solo inventors who meet the criteria in Specifications (1) through (6) in Table 3 (to help control for any truncation bias in the specialization measure - see the discussion of Table 3 in the text). Specification (6) considers the same data as Specification (5), but only looks at cross-sections in the later part of the time period.

(ii) The dependent variable is 0 if an inventor does not switch fields between two consecutive innovations. The field is defined using the 414-category technological class definition of the USPTO. (iii) Normalized Variation in Tree Size is the deviation from the year mean tree size, divided by the year standard deviation in tree size. "Tree size" is the log of the number of nodes in the citations tree behind any patent.

(iv) Technological field controls include dummies for each of Hall et al.’s 36-category measure. 
Table A.1: Number of Observations at Each Stage of Selection

\begin{tabular}{|c|c|c|c|c|}
\hline & $\begin{array}{c}\text { Number of } \\
\text { Observations } \\
\end{array}$ & $\begin{array}{c}\text { Percentage of } \\
\text { Row (3) }\end{array}$ & $\begin{array}{c}\text { Percentage of } \\
\text { Row (4) } \\
\end{array}$ & $\begin{array}{r}\text { Percentage o } \\
\text { Row Above }\end{array}$ \\
\hline (1) Patents Granted & $2,139,313$ & & & \\
\hline (2) Inventors Worldwide & $4,301,229$ & & & \\
\hline $\begin{array}{l}\text { (3) Unique Inventors } \\
\text { Worldwide }\end{array}$ & $1,411,842$ & & & \\
\hline $\begin{array}{l}\text { (4) Unique Inventors with US } \\
\text { Address }\end{array}$ & 752,163 & $53.3 \%$ & & $53.3 \%$ \\
\hline $\begin{array}{l}\text { (5) Unique Inventors, US } \\
\text { Address, Zip Code }\end{array}$ & 224,152 & $15.9 \%$ & $29.8 \%$ & $29.8 \%$ \\
\hline $\begin{array}{l}\text { (6) Unique Inventors, US } \\
\text { Address, Zip Code, Unique } \\
\text { Match from AnyBirthday.com }\end{array}$ & 56,281 & $4.0 \%$ & $7.5 \%$ & $25.1 \%$ \\
\hline $\begin{array}{l}\text { NOTES } \\
\text { (i) Observation counts conside } \\
\text { (ii) A "unique inventor" is defi }\end{array}$ & $\begin{array}{l}975-1999 \mathrm{p} \\
\text { having sal }\end{array}$ & hame, last n & and middle in & \\
\hline
\end{tabular}

Table A.2: The Assignment of Patent Rights

\begin{tabular}{|c|c|c|c|c|c|c|}
\hline \multirow[b]{2}{*}{ Assignment Status } & \multirow[b]{2}{*}{$\begin{array}{c}\text { All } \\
\text { Patents }\end{array}$} & \multirow[b]{2}{*}{$\begin{array}{c}\text { US } \\
\text { Patents } \\
\end{array}$} & \multirow[b]{2}{*}{$\begin{array}{l}\text { US Patents } \\
\text { No zip code }\end{array}$} & \multirow[b]{2}{*}{$\begin{array}{l}\text { US Patents } \\
\text { Zip code }\end{array}$} & \multicolumn{2}{|c|}{ Birth Data } \\
\hline & & & & & $\begin{array}{l}\text { Direct } \\
\text { Match }\end{array}$ & $\begin{array}{l}\text { Other } \\
\text { Patents }\end{array}$ \\
\hline Unassigned & $17.2 \%$ & $22.4 \%$ & $0.4 \%$ & $98.3 \%$ & $97.9 \%$ & $26.6 \%$ \\
\hline US non-govt organization & $43.9 \%$ & $72.9 \%$ & $94.1 \%$ & $0.0 \%$ & $0.0 \%$ & $65.7 \%$ \\
\hline Non-US non-govt organization & $36.2 \%$ & $1.1 \%$ & $1.4 \%$ & $0.0 \%$ & $0.0 \%$ & $3.4 \%$ \\
\hline Other assignment & $2.7 \%$ & $3.5 \%$ & $4.1 \%$ & $1.7 \%$ & $2.1 \%$ & $4.4 \%$ \\
\hline \multicolumn{7}{|c|}{$\begin{array}{l}\text { NOTES } \\
\text { (i) The first column considers all patent observations in the 1975-1999 period ( } 2.1 \text { million observations). } \\
\text { (ii) US patents are those for which first inventor listed with the patent has a US address. } \\
\text { (iii) The Birth Data columns consider those US patents with zip code information for which AnyBirthday.com } \\
\text { produced a birth date. The first Birth Data column considers the specific patents on which AnyBirthday.com was } \\
\text { able to match. The last column considers all other patents by that innovator, identifying the innovator by last name, } \\
\text { first name, and middle initial. } \\
\text { (iv) Unassigned patents are those for which the patent rights were still held by the original inventor(s) at the time } \\
\text { the patent was granted; these patents may or may not have been assigned after the grant date. } \\
\text { (v) Non-government organizations are mainly corporations but also include universities. } \\
\text { (vi) Other assignment includes assignments to: (a) US individuals; (b) Non-US individuals; (c) the US government; } \\
\text { and (d) non-US governments. }\end{array}$} \\
\hline
\end{tabular}


Table A.3: Inventors per Patent, Mean Differences between Samples

Dependent Variable: Inventors per patent

\begin{tabular}{|c|c|c|c|c|c|}
\hline & (1) & $(2)$ & (3) & (4) & (5) \\
\hline $\begin{array}{l}\text { US Address } \\
\text { dummy }\end{array}$ & $\begin{array}{c}-.315 \\
(.0020)\end{array}$ & $\begin{array}{c}-.339 \\
(.0020)\end{array}$ & $\begin{array}{l}-.300 \\
(.0020)\end{array}$ & $\begin{array}{c}-.124 \\
(.0049)\end{array}$ & $\begin{array}{l}-.103 \\
(.0048)\end{array}$ \\
\hline $\begin{array}{l}\text { US Address and Zip Code } \\
\text { dummy }\end{array}$ & $\begin{array}{c}-.786 \\
(.0033)\end{array}$ & $\begin{array}{c}-.670 \\
(.0033)\end{array}$ & $\begin{array}{c}-.769 \\
(.0032)\end{array}$ & $\begin{array}{c}-.155 \\
(.0069)\end{array}$ & $\begin{array}{c}-.176 \\
(.0066)\end{array}$ \\
\hline $\begin{array}{l}\text { US Address, Zip Code, } \\
\text { and AnyBirthday.com } \\
\text { Direct Match dummy }\end{array}$ & $\begin{array}{c}.237 \\
(.0068)\end{array}$ & $\begin{array}{c}.246 \\
(.0067)\end{array}$ & $\begin{array}{l}.212 \\
(.0067)\end{array}$ & $\begin{array}{c}.243 \\
(.0067)\end{array}$ & $\begin{array}{c}.228 \\
(.0066)\end{array}$ \\
\hline Constant & $\begin{array}{c}2.28 \\
(.0014)\end{array}$ & $\begin{array}{c}2.57 \\
(.0023)\end{array}$ & $\begin{array}{c}1.96 \\
(.0052)\end{array}$ & $\begin{array}{c}1.45 \\
(.0042)\end{array}$ & $\begin{array}{l}1.56 \\
(.0067)\end{array}$ \\
\hline $\begin{array}{c}\text { Technological Category } \\
\text { dummies }\end{array}$ & No & Yes & No & No & Yes \\
\hline Grant Year dummies & No & No & Yes & No & Yes \\
\hline Assignee Code dummies & No & No & No & Yes & Yes \\
\hline $\mathrm{R}^{2}$ & .0555 & .0825 & .0756 & .0757 & .1162 \\
\hline
\end{tabular}

NOTES

(i) Regressions consider means in the entire dataset (2.1 million patent observations), covering the 19751999 time period. Standard errors are in parentheses.

(ii) Dummy variables are nested: The second row captures a subset of the first. The third row captures a subset of the second.

(iii) Innovators for whom AnyBirthday.com produces a birth date are often involved with multiple innovations over the 1975-1999 period. The patents used for comparison in this table are those patents for which AnyBirthday.com produced the direct match.

(iv) Regressions with technological category controls are reported using the 6-category measure of Hall et al (2001). Results using the 36-category measure are similar. 

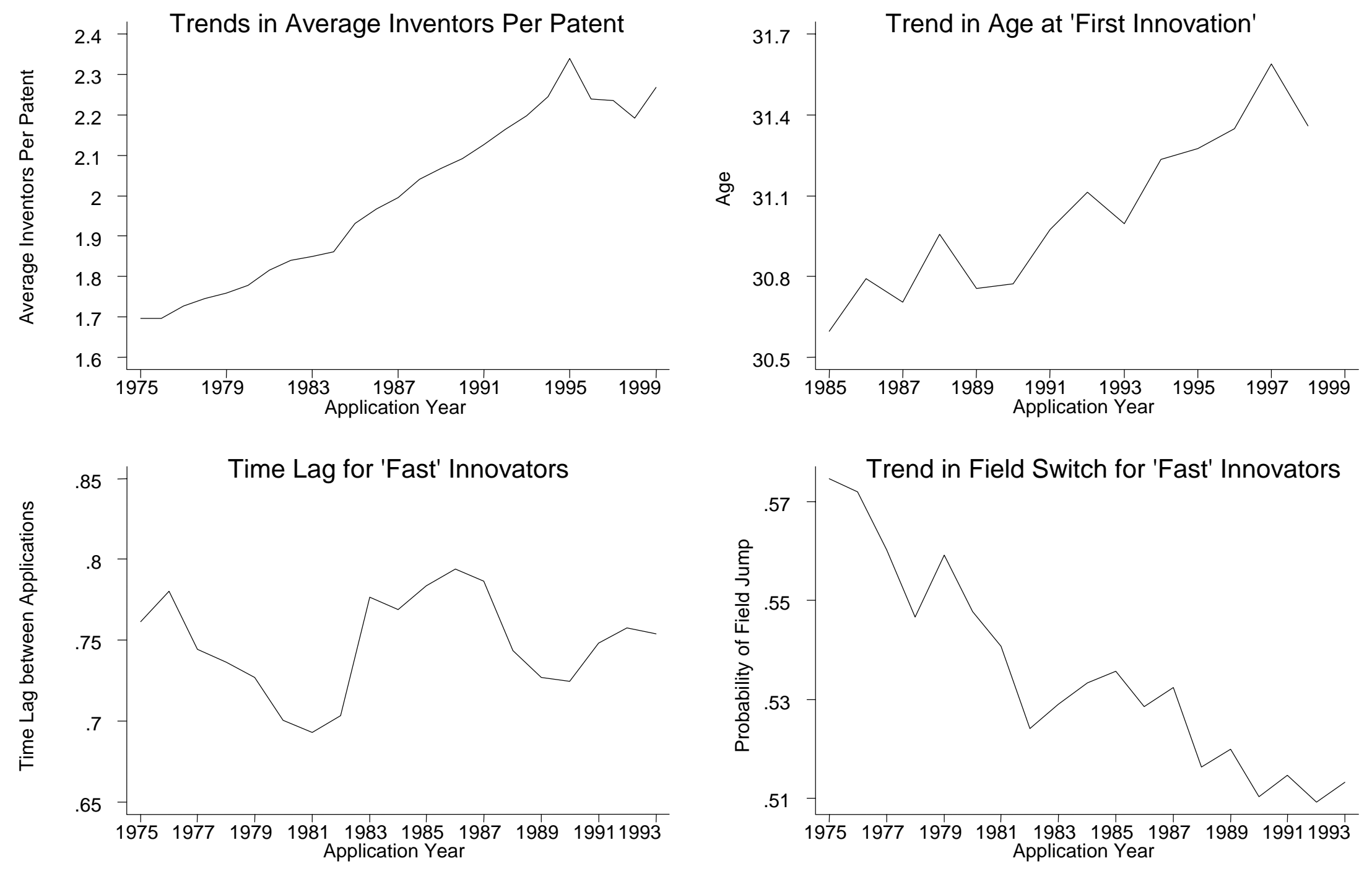

Figure 1: Basic Time Trends 